\title{
Role of Regular Physical Exercise in Tumor Vasculature: Favorable Modulator of Tumor Milieu
}

Authors

Mário Esteves ${ }^{1,2}$, Mariana P. Monteiro3 ${ }^{3}$ Jose Alberto Duarte ${ }^{4,5}$

\author{
Affiliations \\ 1 Laboratory of Biochemistry and Experimental Morphol- \\ ogy, CIAFEL, Porto, Portugal \\ 2 Department of Physical Medicine and Rehabilitation, \\ Hospital-Escola, Fernando Pessoa University, Gondomar, \\ Portugal \\ 3 Unit for Multidisciplinary Research in Biomedicine, \\ Instituto de Ciências Biomédicas Abel Salazar, University \\ of Porto, Porto, Portugal \\ 4 CIAFEL - Faculty of Sport, University of Porto, Porto, \\ Portugal \\ 5 Instituto Universitário de Ciências da Saúde, Gandra, Portugal
}

\section{Key words}

vascularization, perfusion, exercise training, cancer, metastasis

accepted 26.10.2020

published online 11.12 .2020

\section{Bibliography}

Int J Sports Med 2021; 42: 389-406

DOI $10.1055 / a-1308-3476$

ISSN 0172-4622

(C) 2020. Thieme. All rights reserved.

Georg Thieme Verlag KG, Rüdigerstraße 14,

70469 Stuttgart, Germany

\section{Correspondence}

Dr. Mário Esteves

Laboratory of Biochemistry and Experimental Morphology,

CIAFEL R. Dr. Plácido Costa, 91

4200-450 Porto

Portugal

Tel.: + 351915494811 , Fax : + 351225500689

ftmarioesteves@gmail.com

\section{ABSTRACT}

The tumor vessel network has been investigated as a precursor of an inhospitable tumor microenvironment, including its repercussions in tumor perfusion, oxygenation, interstitial fluid pressure, $\mathrm{pH}$, and immune response. Dysfunctional tumor vasculature leads to the extravasation of blood to the interstitial space, hindering proper perfusion and causing interstitial hypertension. Consequently, the inadequate delivery of oxygen and clearance of by-products of metabolism promote the development of intratumoral hypoxia and acidification, hampering the action of immune cells and resulting in more aggressive tumors. Thus, pharmacological strategies targeting tumor vasculature were developed, but the overall outcome was not satisfactory due to its transient nature and the higher risk of hypoxia and metastasis. Therefore, physical exercise emerged as a potential favorable modulator of tumor vasculature, improving intratumoral vascularization and perfusion. Indeed, it seems that regular exercise practice is associated with lasting tumor vascular maturity, reduced vascular resistance, and increased vascular conductance. Higher vascular conductance reduces intratumoral hypoxia and increases the accessibility of circulating immune cells to the tumor milieu, inhibiting tumor development and improving cancer treatment. The present paper describes the implications of abnormal vasculature on the tumor microenvironment and the underlying mechanisms promoted by regular physical exercise for the re-establishment of more physiological tumor vasculature.

\section{Introduction}

The vascular feature of solid tumors was first described in the $19^{\text {th }}$ century with the discovery of blood vessels present in different tumor types (for references, see [1]). Later, tumors were categorized into four regions based on tumor vasculature: (1) avascular necrotic region; (2) seminecrotic region with capillaries, pre-capillaries, and post-capillaries disposed along the avascular necrotic region; (3) stabilized microcirculation region characterized by many venular and venous drainage vessels with few arteriolar vessels; and (4) tumor advance front region with blood flow similar to the host tissue [2]. Generally, peripheral regions show higher blood vessel density than central regions and the ratio of avascular and seminecrotic regions to well-perfused regions is a function of tumor size, with larger avascular regions present in bigger tumors $[3,4]$. 
Today, the defective tumor blood vessel network is recognized as a critical factor impacting variations in tumor microenvironment (TME) and supporting tumor evasion [5]. Indeed, non-functional tumor vessels increase vascular permeability leading to the extravasation of blood to the interstitial space, which precludes effective tumor perfusion [6]. As a result, there is insufficient oxygen $\left(\mathrm{O}_{2}\right)$ supply and waste product removal, which promote the elevation of the interstitial fluid pressure (IFP) and the development of hypoxic and acidic regions [7]. Consequently, the perfusion and action of immune cells progressively become more inefficient and tumor continues to grow, assuming more aggressive phenotypes [7]. Therefore, various modalities of vascular targeting therapies have been explored in order to delay tumor growth [8, 9]. However, since all drugs present side effects and the outcomes regarding vascular therapies have been largely disappointing, non-pharmacological approaches for tumor vascular remodeling have emerged as an important therapeutic field [10]. In this way, the assumption that physical exercise can prevent cancer initiation was suggested in the $20^{\text {th }}$ century and, since then, many investigations have reported that the rate of cancer mortality is inversely related to the levels of physical exercise accomplished $[11,12]$. However, although exercise training has the capacity to modulate multiple biological effects, including metabolism, vascular function, and immunity, little is known about the effects on TME [10]. Therefore, understanding how physical exercise impacts vascular density and tumor perfusion, can create better conditions to improve therapeutic outcomes and potentiate patient care [13]. Thus, the focus of the present review is to describe the implications of abnormal tumor vasculature on TME and to report the candidate mechanisms that may account for the importance and effectiveness of exercise training as a valid therapeutic modality for the reestablishment of more physiological tumor vasculature.

\section{Morphology of Tumor Vessels}

Contrary to physiological angiogenesis, in which new vessels rapidly mature and become stable, tumor blood vessels do not become quiescent, allowing the continuous growth of new blood vessels [14]. As a result, tumor vasculature develops a large series of severe structural and functional abnormalities that are quite distinct from the normal blood vessel network [15]. Indeed, whereas normal vessels are organized in a hierarchical fashion with arterioles, capillaries, and venules that are easily differentiated, tumor vessels lack this orderly branching hierarchy that feed a regularly spaced capillary bed [16]. Instead, tumor vessels are often dilated and tortuous, ranging from capillaries to glomeruloid vessel outgrowths and vascular malformations [17]. As such, the concept of specifically targeting tumor vasculature was proposed and the use of vascular targeting agents (VTAs) was established as a potential therapeutic strategy $[18,19]$. First, vascular disrupting agents (VDAs) were developed to compromise the function of the already established tumor blood vessels [20]. Indeed, VDAs induce direct damage to the endothelium by disrupting its cytoskeleton and adhesion to the matrix and activating local coagulation [21]. The destruction of the endothelium would result in the occlusion of blood vessels and capillary sprouts causing widespread necrosis and secondary ischemic cell death [22]. VDAs are mostly effective against vessels in the central region of the tumor, possibly because the higher IFP in these regions contributes to vascular collapse [23]. However, although the characteristic pattern of central necrosis produced by VDAs can extend up to $95 \%$ of the tumor, a thin viable rim of tumor cells survives at the periphery, which later regrows [24]. Because at the tumor periphery nutritional support is derived from the vasculature of the adjacent normal tissues, these cells can survive VDA treatment, making it an ineffective strategy to eradicate the total tumor mass [25].

Consequently, instead of disrupting the already established tumor blood vessels, the belief that blocking tumor angiogenesis as much as possible would starve tumors to death led to the concept of antiangiogenic therapy [8]. As a sustained growing vasculature is necessary for tumor survival and development, angiogenesis-inhibiting agents (AIAs) seek to inhibit new tumor vessel formation by blocking the angiogenic stimuli through the inhibition of the angiogenic factors and receptor action, thus preventing endothelial cell proliferation, migration, and tube formation [26]. Due to the importance of vascular endothelial growth factor (VEGF) and its receptor VEGFR2 in angiogenesis, there was hope that blocking this pathway would eradicate the tumor vasculature [27]. As such, anti-VEGF antibodies were developed to re-establish the balance between pro- and anti-angiogenic factors and the vascular network of tumors by pruning immature vessels [28-32]. Indeed, some preclinical and clinical studies showed a reduction in vascular density and permeability after angiogenesis-inhibiting treatment [33-35]. However, the effects of such therapy in cancer patients during clinical trials have not fulfilled the expected hopes as the improvement in survival by AIAs was modest, with controversy arising from the finding that after antiangiogenic treatment the levels of tumor hypoxia increased [9, 36, 37]. Indeed, other experimental studies have also demonstrated that AIAs decreased tumor perfusion and the overall distribution of large macromolecules, such as antibodies [38-40]. Following these findings, another two pre-clinical studies presented intriguing evidence showing that VEGF-targeted agents inhibited primary tumor growth but shortened the overall survival by promoting tumor invasiveness and metastasis [41, 42]. In addition, the use of AIAs is likely to mean long-term therapy because after treatment conclusion, dormant tumor cells may regain proangiogenic activity and proliferate $[43,44]$. Therefore, the continuous blockade of the VEGF pathway can lead to vascular collapse and poorly vascularized regions, inducing a more aggressive tumor phenotype [34].

So, modulating the TME by repairing the function of tumor vessels instead of inhibiting it is likely to be a more efficacious strategy to slow tumor progression and enhance cancer treatment [45]. Indeed, the pioneering work of Algire \& Chalkley showed that capillaries in quickly growing tumors have about five times the diameter of those in normal tissue and rarely differentiate into arterioles or venules (for references, see [46]). This difference occurs because vessel walls are compressed by tumor or stroma cells, with some vessels being oversized and others being immature smaller vessels, while in other regions vessels are completely absent [47]. Additionally, tumor vessel walls may have fenestrations, discontinuous or absent basement membranes, fewer pericytes, and less perivascular smooth muscle than normal vessels ( $>$ Fig. 1) [17]. Interestingly, it seems that the judicious application of AIAs might revert much 


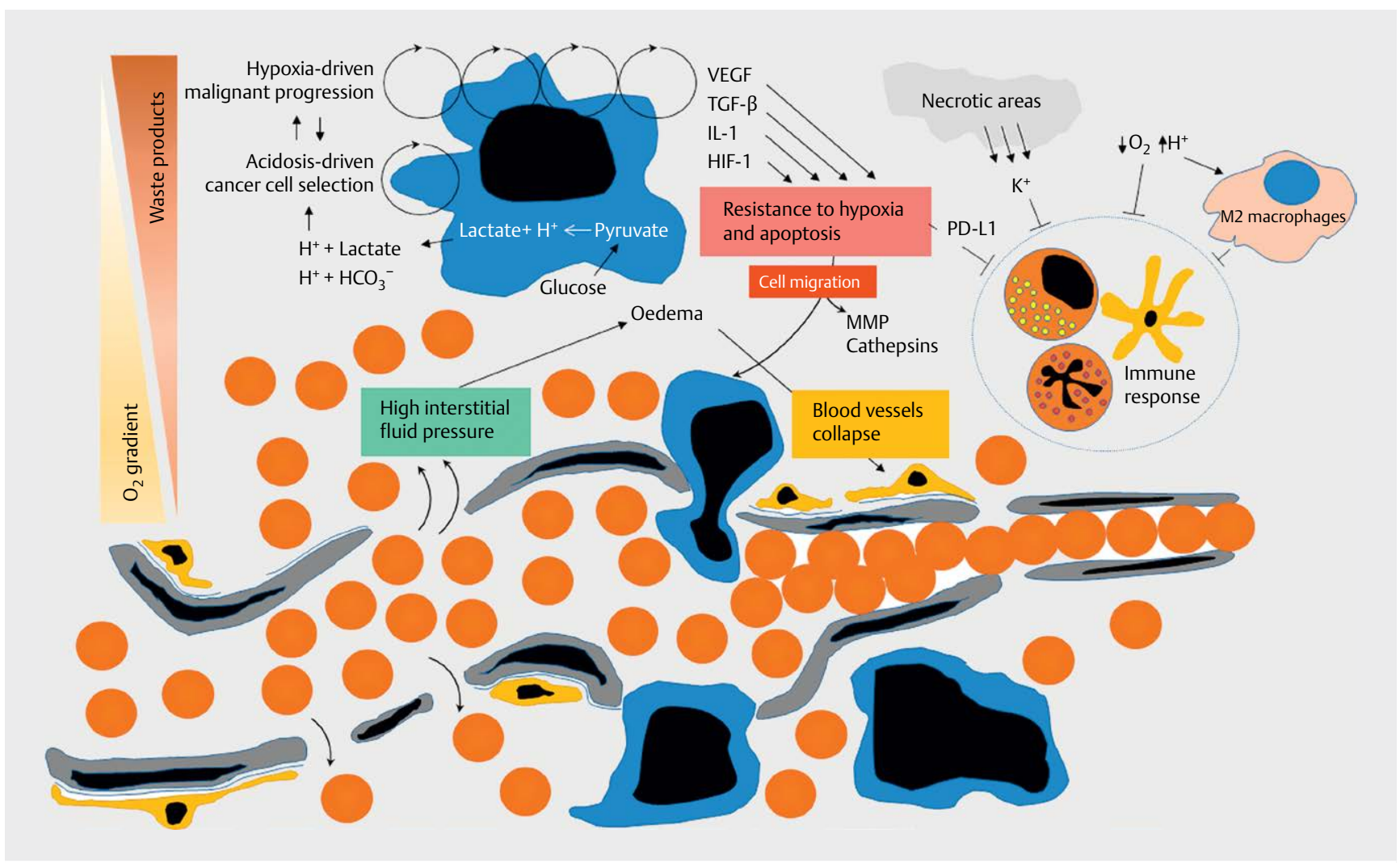

- Fig. 1 Pathological features of tumor microenvironment. The tumor vessel network is chaotic, presenting low pericyte coverage, loose interendothelial cell junctions, and increased leakiness. The resultant high interstitial fluid pressure induces the collapse of blood vessels, leading to the establishment of hypoxic regions. In addition, the glycolytic nature of tumor cells promotes interstitial acidification, which together will impact the immune response, favoring tumor malignant progression. HIF-1, hypoxia inducible factor-1; IL-1, interleukin-1; MMP, metalloproteases; PD-L1, programmed death-ligand 1 ; TGF- $\beta$, transforming growth factor- $\beta$; VEGF, vascular endothelial growth factor.

of the abnormal structure and function of the tumor vasculature down to a level where the tumor vasculature might acquire features similar to the functional and quiescent blood vessels of the normal tissues [48]. Indeed, the presence of a temporary window during anti-angiogenic treatment was already demonstrated, wherein a rebalancing of pro- and antiangiogenic signals occurs to the point that vessels become more functional, improving blood flow and oxygenation in tumor regions that were previously poorly perfused [49]. Given the importance of a good vascularization to allow $\mathrm{O}_{2}$ delivery and the penetration of immune cells into tumor tissue, this strategy aims to turn the abnormal tumor blood vessels into a more functional phenotype by increasing pericyte coverage and basement membrane [50]. Consequently, during the restoring window, tumor vessels become more stable and uniform, reducing the potential for metastasis [51-53]. Pre-clinical and clinical studies already identified this window, typically occurring within 1-2 days after the onset of therapy, followed by a closure coinciding with the loss of functional features (about 6 days) [54]. The window's closure may be related either to the excessively high or prolonged dosing of AlAs or due to the resistance promoted by the activation of alternative pro-angiogenic pathways [54, 55]. Therefore, the transient nature of such therapy means that this approach may be difficult to predict and apply in the clinical setting, thus better strategies to modulate tumor vasculature are still needed [56].
Thus emerging data suggests that the regular practice of physical exercise has a positive impact on vascular remodeling, thus representing a potential non-pharmacological modality to repair tumor vasculature [57-60]. Physical exercise modifies the morphology of vessels along the arterial tree in the skeletal muscle and in the myocardium, increasing its number (angiogenesis) and its diameter (arteriogenesis) [61-63]. The cellular sources of vasodilator compounds during physical exercise include endothelial cells (ECs), erythrocytes, and skeletal muscle. The endothelium releases nitric oxide $(\cdot \mathrm{NO})$, prostacyclin $\left(\mathrm{PGI}_{2}\right)$, and endothelium-derived hyperpolarizing factor (EDHF); skeletal muscles release -NO, ATP, and adenosine; and red blood cells release ATP and -NO [64]. Similarly, regular physical exercise may increase the number of visible tumor vessel lumens and decrease the average sprout length [10]. In a murine model of breast cancer, voluntary running significantly increased the density and maturity of tumor blood vessels, as assessed by $\mathrm{CD} 31^{+}$vessels and desmin-positive pericyte coverage of capillaries, respectively, resulting in decreased tumor growth [58]. Additional studies have corroborated these findings in mouse models of breast and prostate cancer $[60,65]$.

In addition to growth factor signaling, blood vessels are regulated by mechanical cues produced by changes in blood flow, velocity, and pressure [66]. Physical exercise can impact the physical forces acting on blood vessels including shear stress, transmural 
pressure, and cyclic stretch [67]. Specifically, in skeletal muscle, each bout of physical exercise transiently increases shear stress due to higher blood flow, transmural pressure due to a higher blood pressure, and cyclic stretch of blood vessels due to the increased heart rate (HR) and the pulsatile nature of blood flow [68]. Of these, shear stress plays an essential role driving vascular adaptations in contracting muscles. Shear stress, the mechanical force on the endothelium that is critical for the establishment of mature and functional vasculature, is enhanced when mechanosensors recognize higher muscle perfusion and mediates arterial enlargement leading to an acute increase in vascular conductance $[10,69]$. In response to chronic shear stress, ECs hypertrophy, the density of actin microfilaments and focal adhesions increases, and the number of focal adhesion-associated proteins is higher than in cells not exposed to shear stress [70]. Indeed, one of the many effects of aerobic exercise is a systemic increase in blood flow that stimulates the mechanical force on ECs in proportion to exercise intensity ( Fig. 2) [71]. Accordingly, Schadler and co-workers observed a significant increase in blood flow due to aerobic exercise in mice with melanoma and pancreatic tumors that triggered the remodeling of tumor vessels to a more functional state, inhibiting tumor growth [10]. The authors identified a previously unknown shear stress-responsive pathway in ECs, calcineurin-nuclear factor of activated T cells (NFAT)-thrombospondin 1 (TSP-1) signaling, and demonstrated that TSP-1 expression is critical for exercise-induced tumor vascular repair. During increased shear, the activation of calcineurin-NFAT signaling in ECs upregulates the anti-angiogenic protein TSP-1, which promotes the cross-talk between ECs under shear stress and ECs in areas absent of shear, thus inhibiting the proliferation of naive ECs and promoting vascular remodeling [10]. Moreover, due to their narrowness and low blood rate, tumor vessels have been reported to have cancer cells integrated into their walls
[72]. As physical exercise increases blood flow, it could potentially prevent the infiltration of tumor cells in vessel walls and their dissemination to surrounding tissues, thus preventing the development of pre-metastatic niches ( $\mathbf{F i g . ~ 2 ) ~ [ 7 3 ] . ~}$

In tumors, there is also significant arterial-venous shunt perfusion and chaotic vascular organization without any regulation matched to the metabolic demands or functional status of the tissue [74]. Indeed, about $50 \%$ of tumor vessels are non-functional, with vessel walls presenting wide interendothelial junctions and transendothelial channels formed by vesicles and pores more than 100 times the size of those in healthy vessels $[75,76]$. Some studies already showed that the pore size of tumor microvessels varies from $100 \mathrm{~nm}$ to $780 \mathrm{~nm}$ in diameter, while microvessels in normal tissues are less leaky, with tight junctions between $\mathrm{ECs}<2 \mathrm{~nm}$, whereas the pore size in postcapillary venules is larger at up to $6 \mathrm{~nm}$ [77]. In contrast to quiescent ECs, which adhere to the vessel wall, tumor ECs undergo endothelial-to-mesenchymal transition (EMT) and move away from their resident site, leaving behind empty sleeves of endothelial cell-devoid matrix channels, hindering blood flow [78]. Thus, whereas normal vessels are lined with a quiescent monolayer of interconnected adherent ECs that are disposed in the direction of blood flow for optimal perfusion, tumor ECs lose their polarity, detach from the basement membrane and stack upon each other $[79,80]$. Other tumor ECs can die or slough off, establishing gateways for cancer cells that become exposed to the blood [81]. The phenomenon of vessel hyperpermeability is influenced by the activation of the sphingosine-1-phosphate receptors 1 and 2 (S1PR1 and S1PR2) on the surface of ECs, which act as shear stress responsive mechanoreceptors that regulate vessel integrity through their signaling pathways $[82,83]$. Specifically, S1PR1 signaling promotes tight intercellular junction assembly to properly modulate vascular permeability and induce vessel matu-

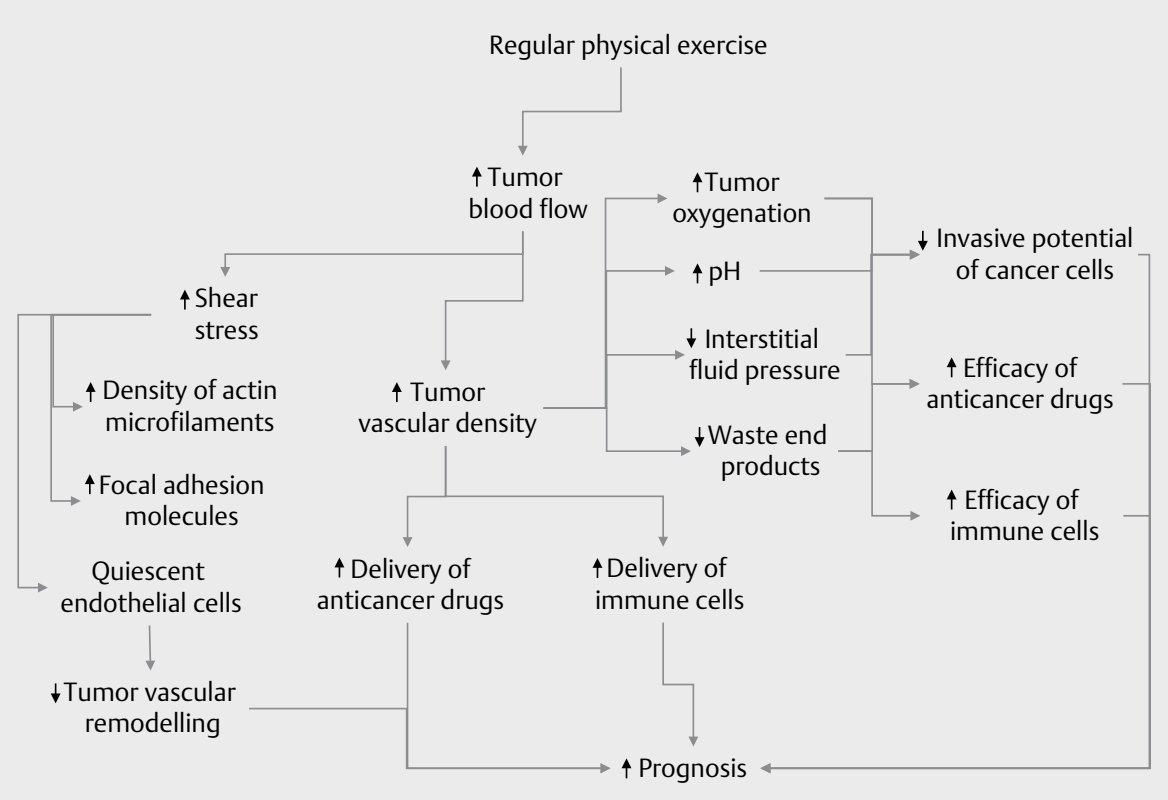

- Fig. 2 Mechanisms linking regular physical exercise with improved cancer prognosis through vascular network changes. 
rity, whereas S1PR2 expression is associated with pathologic endothelium and higher vascular permeability and is upregulated by the disturbed tumor blood flow [84, 85]. The elegant study by Morrel and colleagues showed that two weeks of treadmill running increased S1PR1 and decreased S1PR2 signaling in tumor-bearing mice, reducing tumor vascular permeability and improving tumor oxygenation [57]. These important studies clearly demonstrated that exercise training may have a unique role in tumor vascular repair, eliminating shunts that leave certain tumor regions deprived of blood supply ( $>$ Fig. 2 ).

However, growing tumors continuously demand $\mathrm{O}_{2}$, and because of this high metabolic demand, oncogene activation and exposure to a disturbed microenvironment, tumor cells produce excessive pro-angiogenic factors that render vessels even more abnormal $[86,87]$. Compared to normal tissues, tumors show elevated levels of growth factors like VEGF and vasoactive factors like bradykinin and·NO, which increase vascular permeability even more $[88,89]$. The resultant TME is characterized by heterogeneous hypoperfusion, high IFP, hypoxia, and acidity that favor the shedding of cancer cells into circulation ( $\vee$ Fig. 1) [90].

\section{Abnormal Vasculature and Tumor Microenvironment: The Role of Exercise}

\section{Hypoperfusion}

In vessels, blood flow is directly proportional to the pressure's difference between arteries and veins and inversely proportional to the viscous and geometric resistance [91]. However, due to their continuous remodeling, tumor vessels are leaky and result in higher IFP. Consequently there is an increase in vascular resistance, rendering blood flow not only chaotic but also stagnant in some places, hampering tumor perfusion [92]. Indeed, compared to normal tissues, tumors show greater blood viscosity due to the presence of tumor cells and large molecules like proteins and collagen drained from the extravascular space, and a larger vessel diameter with thin and ragged walls that culminates in increased blood flow resistance $[93,94]$. Furthermore, in a given vessel, blood may travel in one direction and then in the opposite way. These flow patterns, together with the abnormal pressure gradients, hinder the uniform delivery of nutrients, $\mathrm{O}_{2}$, and anticancer drugs $[13,95,96]$. Although disturbances of tumor microcirculation are apparent at early growth stages, blood flow rate tends to decrease with tumor growth $[3,4]$. The pathogenic mechanisms directly responsible for this weight-adjusted flow decline, involve a progressive rarefaction of the vascular bed (decrease in the number of patent vessels/g of tumor), an escalation of the structural and functional abnormalities of the tumor vessel network, and the development of necrosis $[3,97]$. Indeed, most of the blood vessels in the internal region of tumors are veins or venules, whereas peripheral regions have a reduced number of arteries and arterioles [98, 99]. Therefore, the arteriole-venule pressure difference as a driving force for blood flow is negligible in the central region of tumors and greater in the periphery and, consequently, blood flow is lower at the centre and higher at tumor periphery [100]. As a result, the average blood flow in tumors is lower than in normal tissues, with reduced delivery of $\mathrm{O}_{2}$ and nutrients and decreased clearance of by-products of me- tabolism, which leads to hypoxic and acidic regions, mainly in the central part of the tumor ( $\vee$ Fig. 1) [101, 102].

Endurance exercise represents the most potent physiological stimulus for blood vessel remodeling in skeletal muscle [103]. Indeed, vasoactive factors in the muscle interstitium may have a direct effect on ECs and smooth muscle cells in capillaries, inducing conducted vasodilation [104]. Conducted vasodilation is a mechanism to redirect blood flow to the contracting muscles in which the signal for vasodilation travels along the vascular wall, up and downstream, through gap junctions [105]. This mechanism is critical to accurately modulate blood flow as it allows the occurrence of vasodilation in the distant larger vessels that do not necessarily experience the chemical or mechanical stimuli that is present in the working muscle fibers [106]. These adaptations in the blood vessel network elicit the improvement in the regional distribution of blood to assure proper flow in areas of muscle bed vasodilation [71]. Several studies have shown that regular exercise practice is associated with increased vascularization in tumors as well, which is correlated with enhanced blood perfusion and reduced tumor hypoxia (> Fig. 2) [58-60, 107]. Recently, McCullough and colleagues demonstrated that an acute bout of treadmill running increased the prostate tumor blood flow in rats up to $200 \%$, owing in part to the inability of the tumor vasculature to vasoconstrict; importantly, the increase in tumor blood flow resulted in a significant increase in $\mathrm{O}_{2}$ delivery and a $50 \%$ reduction in tumor hypoxic area [60]. During physical exercise, there is a redistribution of cardiac output, with a shunting of blood flow from non-active tissues to the contracting muscles [108]. In part, this shunting is due to the enhancement of sympathetic system activity and the release of norepinephrine that binds to $\alpha$-adrenergic receptors on the vascular smooth muscle, inducing vasoconstriction [109]. Indeed, following physical exercise onset there is an increase in HR driven by the vagal withdrawal and the $\beta$-adrenergic stimulation $[110,111]$. Exercise hyperemia is a highly complex and well structured process that involves sympathetic vasoconstriction and the integration of many vasodilator signals. During physical exercise as the higher sympathetic activity promotes arteriolar constriction, an efficient amount of vasodilators needs to be activated in contracting muscles to promote accurate blood perfusion [112]. This reduced vasoconstriction during contraction (functional sympatholysis) allows adequate $\mathrm{O}_{2}$ delivery to the active fibers. As a result, there is a decrease in $\alpha$-adrenergic responsiveness on the smooth muscle cells, promoting a physical exercise-induced sympatholysis [113]. Accordingly, Heinonen and colleagues found that the inhibition of $\alpha$-adrenergic tone disturbed the perfusion of blood flow to contracting muscles by directing it to the inactive muscle fibers as well [114]. Therefore, the diminished $\alpha$-adrenergic vasoconstriction and the loss of myogenic tone at higher intraluminal pressures of tumor arterioles may inhibit the action of the sympathetic nervous system in tumor vessels, resulting in the enhancement of tumor blood flow during physical exercise [60]. Clinically, this suggests that physical exercise has the potential to improve tumor oxygenation and thus to be able to mitigate the hypoxic microenvironments that are associated with more aggressive tumor phenotypes ( $\triangleright$ Fig. 2) [57, 58, 60].

There are several benefits to improved intratumoral vascularization and blood perfusion: first, there is an increase in tumor oxygenation, preventing the development of intra-tumoral hypoxia; 
second, the accessibility of circulating immune cells is greater; and third, the delivery of anti-neoplastic medication to tumors is facilitated [115-117]. Indeed, tumor blood supply plays an important role in the delivery of therapeutic agents to solid tumors [118]. As tumor cells proliferate more quickly than capillary ECs, these cells force tumor vessels apart creating an unfavorable vascular network for drug delivery, which means that most anticancer drugs show modest effects, in part due to limited penetration into tumor cells [91]. Nacev and co-workers observed that tumor cells are often located $100 \mu \mathrm{m}$ away from the nearby vessels, whereas in normal tissues, cells are closer to capillaries $(50-100 \mu \mathrm{m})$ [119]. As drug molecules need to travel a longer distance and the commonly used cytotoxic agents like doxorubicin (DOX) are unable to penetrate more than $40-50 \mu \mathrm{m}$ from blood vessels, there is an insufficient drug penetration rate to kill cancer cells [120].

Indeed, it has been shown that exercise training may also improve the penetration of chemotherapeutic agents into tumors ( $\vee$ Fig. 2). The study of Schadler and collaborators demonstrated that exercised mice with pancreatic adenocarcinoma presented a $24 \%$ increase in functional vessels and improved the delivery of gemcitabine to tumors [10]. Further, to investigate the delivery of DOX to tumors, Morrel et al. submitted mice with Ewing's sarcoma to a moderate-intensity exercise training protocol and concluded that tumors from exercised mice had significantly higher DOX levels than tumors from sedentary mice [57]. As such, these studies additionally reinforce the importance of functional tumor vasculature to access TME, and physical exercise seems to be a viable option to achieve it.

\section{High Interstitial Fluid Pressure}

The interstitial space mediates the exchange of $\mathrm{O}_{2}$, nutrients, and waste products between the vascular system and cells, and the movement of fluid across the vessel wall is governed by the difference in hydrostatic and oncotic pressures (Starling's forces) [121]. In human capillaries, the oncotic pressure is about $28 \mathrm{mmHg}$, which tends to keep fluid in the capillaries [122]. Contrarily, the capillary hydrostatic pressure $(20 \mathrm{mmHg})$, the interstitial-fluid osmotic pressure $(8 \mathrm{mmHg})$, and the interstitial-fluid hydrostatic pressure $(-1$ to $-3 \mathrm{mmHg}$ ) tend to move fluid out from the capillaries [123]. As such, normally there is a net outward filtration pressure from the capillaries into surrounding tissues of $1-3 \mathrm{mmHg}$ [122]. This outward pressure guarantees a flow of fluid out from the vessels and through the interstitium, contributing to the transport of molecules to and from cells [123]. However, in tumors, the incomplete or even missing endothelial lining and discontinuous basement membranes increase vascular permeability with extravasation of blood to the interstitial space ( $\vee$ Fig. 1) $[75,124]$. Indeed, it was already shown in normal tissues that the physiological influx of water into the interstitial compartment varies between 0.5 and $1.0 \%$ of plasma flow, but in tumors this value reaches more than 15\% [125]. Consequently, tumors are characterized by higher geometric and viscous resistance to blood flow, increased microvascular hydrostatic pressure, high resistance to interstitial fluid flow, and impaired lymphatic drainage, resulting in the drastic elevation of the IFP [126-129]. In normal tissues IFP is just above or below atmospheric values ( -3 to $+3 \mathrm{mmHg}$ ), but in tumors it is generally high at the center, reaching values of $50-100 \mathrm{mmHg}$ and drops steeply at the tumor periphery [130]. This interstitial hypertension causes edema, leading to sluggish blood flow due to the clogging of red blood cells and to the collapse of blood vessels, particularly at the centre of the tumor, triggering the proliferation of cancer cells ( $\triangleright$ Fig. 1) [131]. Therefore, functional vessels are present mainly in the tumor periphery, where there is a drop of the IFP to a more physiological level $[132,133]$.

In many tumors the supportive stroma also contributes to the increase of IFP, through the release of cytokines, growth, and angiogenic factors, which in turn can compress intratumoral vessels, impairing their function [134]. The resultant edema associated with the tumor's high osmotic pressure forms a barrier to adequate infiltration of immune cells and delivery of anticancer drugs [135]. Since IFP was identified to be significantly higher in tumors compared to normal tissues, an enhanced IFP has been observed in several solid tumors and it has been considered a critical prognostic factor $[136,137]$. Indeed, in the study of van der Voort van Zyp et al., an increased extracellular pressure of just $15 \mathrm{mmHg}$ was enough to stimulate colon cancer cell adhesion to surgical wounds, leading to tumor recurrence [138]. Based on these data, it has been suggested that tumor IFP forms a link between tumor angiogenesis, tumor hypoxia, and metastasis in which dysfunctional angiogenesis led to the development of a vascular network with serious architectural abnormalities [139]. The result is a TME characterized by elevated IFP and hypoxic regions that promotes the upregulation of pro-angiogenic factors, forcing the interstitial fluid to flow from the center to the tumor periphery where stimulates tumor hemangiogenesis, peritumoral lymphangiogenesis, and consequently lymph node metastasis [139].

Therefore, strategies capable of lowering fluid accumulation in tumors by decreasing the leakiness of tumor vessels or by draining the interstitial fluid should lower the levels of tumor IFP [140]. In this way, by improving vascular maturity, physical exercise may lead to a decrease of non-functional sprouts and an increased hierarchical vasculature with reduced leakiness that may attenuate IFP [55]. Decreasing the level of IFP could potentiate macromolecular and nanoparticle drug transport ( $>1000 \mathrm{MW}$ ), because the transport of these drugs is governed by the pressure gradient across the vessel wall [120]. Indeed, Betof and co-workers studied the effect of exercise training in mice with breast cancer under chemotherapy treatment and observed an increase in the amount of viable tumor area containing pericyte-covered vessels $(p=0.006)$, an increased vessel area covered by pericytes $(p=0.024)$, and a 3- to 4 -fold higher rate of mature vessels when compared to sedentary animals; as a result, the rate of tumor growth was significantly lower [58]. Similarly, in the study of Morrel and collaborators, two weeks of treadmill running promoted the remodeling of tumor vasculature, significantly reducing vessel permeability; however the authors did not observe any impact on tumor growth [57].

In contractile muscles, fluid filtration from the blood to the interstitium markedly increases during acute physical exercise. Indeed, because the movement of fluid initially exceeds the capacity of the lymphatic system, interstitial fluid volume significantly increases at the onset of physical exercise [141]. The transient enhancement of IFP occurs because capillary hydrostatic pressure is higher due to the arteriolar vasodilation, the increased microvascular surface area, the increased muscle vessel density, and the high- 
er osmotic concentration that results from the release of metabolites during skeletal muscle contraction [142]. However, with the continuation of physical exercise, transcapillary fluid movement slows to the point that lymphatic drainage and net filtration are in balance, blocking the accumulation of fluid [141]. As physical exercise-induced hypervolemia is associated with higher plasma albumin content, there is a reduced transcapillary escape rate (TER) of albumin and a redistribution from the interstitial to the intravascular compartment [143-145]. Accordingly, Mack and collaborators verified that in contracting muscles the decrease in hydrostatic pressure and increased oncotic pressure promoted a higher lymphatic return of fluid and protein to the vascular compartment [144].

Thus, by enhancing draining volume flow, the skeletal muscle contraction acts as an edema safety agent to limit the increase in IFP [146]. Indeed, the removal of tissue proteins produces a filtrate of plasma that becomes progressively protein-poor in concentration, which decreases the colloid osmotic pressure of interstitial fluid. Consequently, the transcapillary oncotic pressure increases, reducing fluid accumulation in tissues [147]. Physical exercise can prevent the elevation of IFP by different mechanisms. First, the contraction of muscle fibers acts on lymphatics by pumping lymph into the collecting vessels [146]. Second, physical exercise also boosts blood from contracting skeletal muscle by the action of muscle pump, which mitigates the higher capillary pressure induced by arteriolar vasodilation [71]. Finally, the decreased postcapillary resistance induced by muscle contraction also limits the accumulation of interstitial fluid during physical exercise [141].

Collectively, these data suggest that physical exercise could be a potential strategy to prevent high tumor IFP, but further research is still needed.

\section{Oxygen Deprivation}

Normally, tumor cells proliferate faster than ECs, reducing vascular density particularly at the center of the tumor, turning it very distant from the blood supply $(>100 \mu \mathrm{m})$ [148]. Due to the poorly organized vascular architecture, irregular blood flow, and the compression of blood and lymphatic vessels, the $\mathrm{O}_{2}$ consumption rate of neoplastic cells may outweigh an insufficient $\mathrm{O}_{2}$ supply, resulting in the development of areas of very low oxygenation [149].

Because TME also depends on the cellular consumption of $\mathrm{O}_{2}$ and essential nutrients, tumor cells closer to the vascular supply consume what they need for growth and survival, with less being available for those cells further away. Consequently, radial $\mathrm{O}_{2}$, nutrients, and $\mathrm{pH}$ gradients are established ( $\vee$ Fig. 1) [97]. Indeed, it has been reported that the $\mathrm{O}_{2}$ partial pressure $\left(\mathrm{pO}_{2}\right)$ of cells next to capillaries can be as low as $15 \mathrm{mmHg}$, which will reduce the $\mathrm{O}_{2}$ diffusion distance [150]. All these factors will result in the development of regions of necrosis, which are commonly observed in advanced solid tumors, reflecting the consequences of prolonged periods at $\mathrm{O}_{2}$ levels that are insufficient to maintain cell viability ( Fig. 1) [151].

Primarily, hypoxia leads to the loss of proliferative capacity and finally to death of normal and most cancer cells [102]. On the other hand, some tumor cells can survive hypoxia-induced cell death by triggering alterations in the proteome and/or genome, favoring tumor development. This phenomenon is called the "Janus face of hypoxia" [152]. Indeed, the critical $\mathrm{pO}_{2}$ in tumors below which the harmful changes related to decreased $\mathrm{O}_{2}$ consumption have been observed is $8-10 \mathrm{mmHg}$ [153]. Specifically, the pioneering work of Kolstad shows that whereas $\mathrm{pO}_{2}$ is about $36 \mathrm{mmHg}$ in normal cervical mucosa, in cervical cancer it progressively drops to $5 \mathrm{mmHg}$ with the development of the disease [154]. These data are indicative of inadequate tissue oxygenation, most probably due to a restriction of the microcirculation and thus a restriction of $\mathrm{O}_{2}$ availability to cancer cells in vivo. This phenomenon gets significantly worse with tumor growth [3]. Evidence shows that $50-60 \%$ of locally advanced solid tumors may present hypoxic and/or anoxic regions that are heterogeneously distributed within the tumor mass [155]. Tissue hypoxia results in the stabilization of the hypoxia-inducible factor (HIF) because in normoxic conditions the HIF- $\alpha$ units are unstable and quickly degraded by the proteasome pathway through the ubiquitin $\mathrm{E} 3$ ligase complex, the recognition component of which is the von Hippel Lindau (VHL) [156]. However, since very low $\mathrm{O}_{2}$ levels are available for hydroxylation under hypoxic conditions, the HIF- $1 \alpha$ subunit is stabilized, forming a heterodimer with HIF-1 $\beta$ to functionally mediate an array of genes involved in angiogenesis, metabolism, tumor cell survival and proliferation, drug and radiation resistance, and immune evasion $[157,158]$. As a result, during hypoxia-driven malignant progression, the capacity for local invasive growth and perifocal tumor cell spreading and dissemination is higher $[159,160]$. Indeed, hypoxia enhances the invasive potential of tumors through the activation of pro-migratory proteins and pro-invasive extracellular matrix (ECM) molecules [161]. The first clinical study demonstrating a clear association between tumor hypoxia and the likelihood of distant metastasis was reported by Brizel and co-workers, who observed that the $\mathrm{pO}_{2}$ of metastasizing tumors $(7.5 \mathrm{mmHg}$ ) was significantly lower than the non-metastasizing tumors $(20 \mathrm{mmHg})$ [162]. Additionally, hypoxia-induced inhibition of gene expression was observed for cell-surface integrins favoring tumor cell migration [163]. Indeed, the first study involving the exposure of murine fibrosarcoma cells to different $\mathrm{O}_{2}$ concentrations showed that the more hypoxic the exposure, the greater number of metastases developed [164]. At the same time, recent evidence suggested that hypoxic cells are resistant to radiation therapy and can repopulate the tumor due to the presence of cancer stem cells in hypoxic regions $[165,166]$. Finally, in the presence of $\mathrm{O}_{2}$, most anticancer drugs produce free radicals that damage DNA [167]. These drugs accept electrons from biological sources and then transfer them to $\mathrm{O}_{2}$ [168]. However, at low $\mathrm{O}_{2}$ concentrations the cytotoxicity of these drugs, whose activity is mediated by free radicals, is decreased and the elimination of the tumor is ineffective [169].

Collectively, these observations may explain why intratumoral hypoxia favors tumor growth and dissemination, correlating it with a poor prognosis in many human cancers [170]. Unfortunately, today there is no accepted standard of care for reducing tumor hypoxia. Nevertheless, to maintain homeostasis, $\mathrm{O}_{2}$ supply and demand in skeletal muscle occurs in a dynamic balance and may be modified by changes in blood flow, $\mathrm{O}_{2}$ tension and by the number of capillaries participating in gas exchange [171]. Indeed, $\alpha$-adrenergic response to physical exercise causes vasoconstriction of inactive regions, redirecting blood flow to the working muscles to match the increased demand for $\mathrm{O}_{2}$ [103]. To this end, the splanchnic circulatory system that accounts for about $25 \%$ of car- 
diac output at rest, markedly decreases during physical exercise [172]. Similarly, renal flow also decreases proportionally with increasing exercise intensity. Endo and colleagues (2008) noted that even cycling ergometer exercise for $4 \mathrm{~min}$ at $40 \mathrm{~W}$ decreased blood flow to the kidneys by $20 \%$ [173]. Inversely, physical exercise-induced hyperemia increases the recruitment of non-perfused capillaries in contracting muscles, which not only improves the surface area available for gas exchange but also decreases diffusion distance for $\mathrm{O}_{2}$ flux [174]. Indeed, the flux of $\mathrm{O}_{2}$ in skeletal muscles during physical exercise can increase 100 -fold over resting values [175]. At rest and during physical exercise, skeletal muscle oxygenation depends on the fine-tuning between $\mathrm{O}_{2}$ delivery through the microcirculation and $\mathrm{O}_{2}$ consumption by the skeletal myocytes [176]. The transport of $\mathrm{O}_{2}$ through the microcirculation is accomplished by convection and diffusion [177]. Convection is an efficient way to move $\mathrm{O}_{2}$ in blood over large distances, mostly in the larger arterial and venous vessels. In peripheral tissues $\mathrm{O}_{2}$ moves short distances by diffusion from the terminal vascular sites to nearby parenchymal cells, where it is utilized by the mitochondria [178]. In this way, in contracting muscles, due to increased capillarization and a bigger exchange surface area, there is higher arterio-venous $\mathrm{O}_{2}$ extraction, which improves $\mathrm{O}_{2}$ diffusion to the cells [179]. Indeed, it was shown that during physical exercise, $\mathrm{O}_{2}$ consumption can increase up to a point that $70-80 \%$ of the $\mathrm{O}_{2}$ delivered to the active muscles may be extracted [180].

Also, the chronic adaptations of skeletal muscle to exercise training leads to better aerobic performance at higher intensity through an improvement in metabolic capacity and $\mathrm{O}_{2}$ supply [181]. Supporting this notion, it was observed that after exercise training there is an increased mitochondrial enzymatic content, which is associated with larger diffusional $\mathrm{O}_{2}$ conductance and increased $\mathrm{O}_{2}$ extraction [182, 183]. In addition, two-legged acute exercise after 4 weeks of unilateral knee-extensor training, resulted in higher HIF$1 \alpha$ concentration only in the untrained leg [184]. Similarly, 6 weeks of endurance training showed increased expression of HIF- $1 \alpha$ inhibitors that led to an attenuated PDK-1 expression, thus increasing the muscle capacity to utilize $\mathrm{O}_{2}[185]$. Therefore, it seems that exercise training can improve $\mathrm{O}_{2}$ delivery and extraction, attenuating the acute HIF- $1 \alpha$ response and enhancing oxidative metabolism [181].

Accordingly, the physiological effects of physical exercise as an inhibitor of tumor hypoxia have already been shown ( $\mathbf{F i g}$. 2) [58-60]. Betof and colleagues reported that voluntary running throughout tumor development decreased the hypoxic fraction by $50 \%$ [58]. McCullough and collaborators also verified that the practice of chronic exercise significantly improved microvascular $\mathrm{pO}_{2}$ and decreased the hypoxic fraction within the prostate tumors of rats compared with their sedentary counterparts [59]. Additionally, the same author studied the acute effects of exercise training on tumor hypoxia and verified that a single bout of treadmill running reduced the tumor hypoxic fraction by $15 \%$ [60]. This means that exercise training immediately promotes adaptations on TME that can be exploited to mitigate hypoxia and cancer progression.

\section{Acidic pH}

In tumors, the development of hypoxic regions promotes the activation of genes involved in the regulation of glycolysis, increasing glucose consumption and leading to the extrusion of lactic and carbonic acid outside the cell [186]. The result is ineffective clearance of by-products of metabolism that lowers the interstitial $\mathrm{pH}$, leading to tumor acidosis ( $\mathrm{ml} / \mathrm{g} / \mathrm{min}$ tumor venous blood become acidic and $\mathrm{pH}$ falls below 7.0 , which means that tumor tissue acidosis mainly develops because of inadequate drainage [188]. This was true for several tissue samples from cancer patients that were shown to be acidic, with an extracellular $\mathrm{pH}$ ( $\mathrm{pHe}$ ) of 5.6 to 6.8 , whereas the $\mathrm{pHe}$ of normal tissues is significantly more alkaline, at 7.2-7.5 [189, 190]. In contrast, the cytosolic $\mathrm{pH}$ of tumor cells is commonly preserved at a slightly more alkaline level (7.2-7.5), acting as a pre-requisite for effective protein and DNA synthesis and cell survival [191]. In order to ensure this pattern, tumor cells secrete the excessive produced acids and protons to the extracellular space [192]. However, as quickly growing tumor cells exhibit high glycolytic rates and high lactate production together with insufficient drainage, there is an accumulation of $\mathrm{H}^{+}$in the respective tissue [193]. The result is an acid-outside $\mathrm{pH}$ gradient typically in opposition to that observed in normal tissues in which intracellular $\mathrm{pH}(\mathrm{pHi})$ is lower than $\mathrm{pHe}$ [194].

In addition to non-optimal vascularization and drainage, the development of tumor acidosis can also occur through the availability of glucose to hypoxic cancer cells, which usually occurs because the diffusion distance for glucose is larger than for $\mathrm{O}_{2}$ [97]. This was first noted by Kallinowski et al., when the authors observed that the hypoxic tumor cells distant from the supplying vessel could still cleave glucose to lactic acid [195]. Therefore, it is not unusual to observe an inverse correlation between the lactic acid content and the interstitial pH in many tumors [196]. Although lactate was initially thought to be just a glycolytic waste product, it is now established that it can be consumed by aerobic tumor cells, thus reserving glucose for distant hypoxic tumor cells [197]. So, sharing of energy substrates between aerobic and hypoxic tumor cells is a key mechanism for the survival of hypoxic tumor cells [198]. Indeed, acidosis causes additional stress on cancer cells, leading to the selection of cells that are best prepared to withstand harsh conditions, likely owing to the acquisition of specific mutations, including the activation of VEGF, transforming growth factor (TGF)- $\beta$, interleukin (IL)-1 and HIF-1 [199, 200]. Together, these mutations turn tumor cells in the acidic regions more resistant to cell death than in normally perfused regions [192]. These observations led to the development of the "acid-mediated invasion hypothesis" in which tumor acidification favors tumor cell migration by enhancing tumor cell resistance and ECM degradation through the activity of matrix metalloproteases (MMP) and cathepsins, thus creating the pre-condition for tumor dissemination ( $>$ Fig. 1) [186].

Low $\mathrm{pH}$ levels have also been shown to decrease the radiosensitivity of cells and to modulate the cytotoxicity of certain anticancer drugs [201]. Indeed, as in tumors pHe is low and the pHi is alkaline, weakly basic drugs with an acid dissociation constant of 7.59.5, such as DOX and mitoxantrone, are protonated, displaying decreased cellular uptake [202]. Interestingly, the acidic TME has also been shown to be partially responsible for unsuccessful antiangiogenic therapies. Faes and collaborators showed that exposure 
to an acidic milieu of $\mathrm{pH} 6.4$ decreased the expression of VEGFR-2 in ECs, making AIAs inefficient [203]. Taken together, it seems that tumor cells have the ability to adapt to a low pHe, activating mechanisms for cancer survival and proliferation [193]. Because this acidic milieu is so favorable for tumor migration, strategies to rebalance the $\mathrm{pH}$ levels of cancer cells are a viable option in complex anticancer treatment [204].

In resting skeletal muscles, the regulation of $\mathrm{pHi}$ depends on passive membrane fluxes of hydrogen ions $\left(\mathrm{H}^{+}\right)$and bicarbonate, and membrane transport systems mediating a secondary active transport, thus balancing the acidic load [207]. However, muscular contraction induces several chemical, physical, and physiological challenges within and outside the cells. Therefore, as a consequence of intense physical exercise, the formation of lactate, carbon dioxide $\left(\mathrm{CO}_{2}\right)$, and $\mathrm{H}^{+}$induces intracellular acidosis [208]. The physiological adaptation to these insults involves a quick and intense increase in ventilation to match the higher $\mathrm{O}_{2}$ demand and to remove $\mathrm{CO}_{2}$, and the increase of lactate- dependent and lactateindependent $\mathrm{H}^{+}$transport [209, 210]. At low-intensity physical exercise, as lactate formation is low, $\mathrm{H}^{+}$removal is managed mainly by the sodium $\left(\mathrm{Na}^{+}\right)$-dependent transport system and involves $\mathrm{Na}^{+} / \mathrm{H}^{+}$exchange and $\mathrm{Na}^{+} /$bicarbonate co-transport, whereas lactate-dependent $\mathrm{H}^{+}$removal plays a minor role [207]. Nevertheless, because after high-intensity physical exercise the lactate concentration may reach $40 \mathrm{mM}$ with extensive $\mathrm{H}^{+}$release from the contracting cells, the pHi of skeletal muscle may decrease to 6.5 [211]. Therefore, the lactate $/ \mathrm{H}^{+}$and $\mathrm{Na}^{+} / \mathrm{H}^{+}$carriers increase to mediate lactate and $\mathrm{H}^{+}$efflux. Indeed, during high-intensity physical exercise both systems increase, but lactate-independent $\mathrm{H}^{+}$removal quickly reaches its maximal capacity, whereas lactate-dependent $\mathrm{H}^{+}$removal can increase by at least five times. Therefore, the lactate $/ \mathrm{H}^{+}$co-transporters seem to be the most important systems to remove $\mathrm{H}^{+}$during high-intensity physical exercise [207].

Importantly, the regulation of $\mathrm{pH}$ in blood and skeletal muscle can adapt in response to exercise training and the beneficial effect of training has been described at the protein and functional level [207]. Indeed, exercise training can increase the density of the lactate $/ \mathrm{H}^{+}$co-transporter proteins MCT1 and MCT4, and the capacity to transport lactate and $\left.\mathrm{H}^{+} 212,213\right]$. Also, the amount of the $\mathrm{Na}^{+} / \mathrm{H}^{+}$exchanger protein NHE1 increased in humans after 8 weeks of submaximal exercise training [212]. Similarly, soleus $\mathrm{Na}^{+} /$bicarbonate transporters of Wistar rats were shown to increase after 5 weeks of high-intensity training [214]. On the other hand, the improved blood flow induced by physical exercise probably contributes to the increased release of $\mathrm{H}^{+}$and lactate with training. Indeed, the involvement of increased blood flow is consistent with the finding that a better washout of lactate and $\mathrm{H}^{+}$can occur with smaller muscle-to-arterial concentration gradients after exercise training [207]. $\mathrm{Na}^{+} /$potassium $\left(\mathrm{K}^{+}\right)$homeostasis also improved in trained subjects, representing another mechanism through which exercise training potentiates $\mathrm{pH}$ regulation in skeletal muscle [215].

Therefore, given that exercise training can decrease lactate and $\mathrm{H}^{+}$levels, it is possible that acidic TME could also be impacted ( $>$ Fig. 2). Currently, there are no reports on how physical exercise affects tumor $\mathrm{pH}$. However, treadmill running in mice with mammary carcinomas reduced tumor and circulating lactate concen- trations by approximately $17 \%$ compared with sedentary counterparts [205]. Accordingly, Bacurau et al. also reported that a moderate-intensity treadmill running protocol significantly decreased glucose consumption and lactate production in rats with Walker-256 tumors [206]. Nonetheless, as evidence is lacking, future studies are required.

\section{Immunosuppression}

The impaired vascular supply of tumors and the consequent hostile TME characterized by hypoxia and acidosis hampers T-cell infiltration, function, and survival [216]. Physiologically, immune cells permanently patrol tissues to signal and remove pathogens, foreign antigens, and abnormal cells [217]. However, under hypoxic and acidic conditions there is an upregulation of growth factors and cytokines that inhibit the activity of T-cells and the ability of dendritic cells (DCs) to process and present tumor antigens ( $>$ Fig. 1) [218-220]. Although poor lymphocyte infiltration due to an abnormal tumor vasculature represents the main reason for the immune failure in the elimination of cancer cells, the presence of immune suppressive agents in the TME is also important because it leads to T-cell dysfunction in the context of anergy, senescence, and exhaustion [221]. Consequently, the immune cells that successfully infiltrate in the TME are not fully effective [222].

A critical player of the metabolic reprogramming in the TME is hypoxia, and cells of both innate and adaptive immunity are very sensitive to these conditions, because it was shown that hypoxia can regulate aggregation, invasion, and motility of macrophages and neutrophils, favoring local inflammation and immunosuppression $[223,224]$. Low $\mathrm{O}_{2}$ levels can also impact T-cell differentiation by changing the balance toward a T helper (Th) $17 / \mathrm{T}$ regulatory (Treg) phenotype and impairing the cytotoxic properties of natural killer (NK) cells [225]. Additionally, hypoxia can inhibit T-cell function by exacerbating glucose deprivation, reducing cytosolic levels of calcium $\left(\mathrm{Ca}^{2+}\right)$, which is essential for cytokine production and promoting excessive formation of reactive oxygen species (ROS) [226]. Indeed, it was proved that hypoxia can upregulate programmed death-ligand 1 (PD-L1) on tumor cells, which in turn dampens T-cell function by interacting with the inhibitory receptor programmed cell death protein 1 (PD-1) on the T-cell surface ( Fig. 1) [227]. Hypoxia also upregulates indoleamine 2,3-dioxygenase (IDO) expression in DCs, which promotes Treg survival and function, inhibiting the generation of effector CD4 ${ }^{+}$and $C D 8^{+}$ $T$ cells [228]. In addition, IDO leads to the upregulation of several cytokines like IL-6, IL-10, and TGF- $\beta$, further accentuating the immunosuppressive state [229].

Inefficient tumor vasculature and subsequent hypoxia lead to the development of necrotic foci, a very common feature of solid tumors [230]. Necrosis within TME results in increased concentrations of $\mathrm{K}^{+}$, which suppresses T-cell function ( $\mathbf{F i g} .1$ ) [231]. Indeed, $\mathrm{K}^{+}$released by necrotic cells, can be internalized by infiltrating $T$ cells, inhibiting their effector functions due to the downregulation the Akt/mTOR signaling [232]. Besides, abnormal tumor vasculature not only deprives TME of $\mathrm{O}_{2}$ and nutrients, but it also fills it with byproducts of metabolism, some of which display immune suppressive activities [233]. Indeed, the degradation of glucose into lactate results in the acidification of the TME that further suppresses T-effector functions [220, 234]. At reduced $\mathrm{pH}$, poly- 
morphonuclear leukocytes (PMNs) display reduced chemotaxis and respiratory and bactericidal capacity, and lymphocyte cytotoxicity is also inhibited [235]. Further, low pH levels increase the suppressive activity of tumor-infiltrating myeloid derived suppressor cells (MDSCs) and tumor-associated macrophages (TAMs), reducing the proliferation of cytotoxic T-lymphocytes (CTLs) in the TME ( $>$ Fig. 1) [236]. The inhibitory effects of acidic $\mathrm{pH}$ on effector T-cell response in the TME is associated with generalized T-cell anergy, impaired cytokine secretion, and decreased perforin degranulation [237]. In addition, Soriano and colleagues observed that tumors also escape $\mathrm{CD}^{+}{ }^{+}$T-cell-induced cytotoxicity by overexpressing the inhibitors of perforin/granzyme pathway. In their study, the authors found that tumors showed an increased expression of protease inhibitor-9, a granzyme-B inhibitor [238]. Consequently, the capability of CTLs to kill tumor cells is reduced by one half [239]. Thus, similar to hypoxia, tumor acidity negatively regulates tumor-specific effector T cells, contributing to the dysfunction of antitumor immunity [240]. Therefore, alternative strategies to increase T-cell activation, infiltration, and cytotoxicity remain one of the main challenges today [241].

Immune recognition and elimination are important intrinsic mechanisms against tumors and their immunological profile is strongly associated with cancer prognosis [242]. A general model of exercise-driven modulation of immune cell distribution in tissues was proposed, describing the way that NK cells, T cells and B cells are mobilized to the blood [243]. This action seems to represent the recruitment of stored immune cells and not the formation of new ones [244]. Indeed, both local and systemic effects of physical exercise may potentiate T-cell incursion into tumors [245]. First, it increases circulating levels of IL-6, which can upregulate the adhesion molecules on tumor vascular endothelium, thus enhancing T-cell trafficking [246]. Second, exercise training causes redistribution of NK and $\mathrm{CD} 8^{+} \mathrm{T}$ cells that have cytotoxic activity against cancer cells, increasing their concentrations approximately 10 -fold and 2.5-fold, respectively [247]. Physical exercise can also influence the immune system by regulating Th1 and Th2 responses. The increase in Th1-type cytokine (IL-12 and interferon gamma (IFN-y)) production and T-box transcription factor (T-bet) expression after exercise training may contribute to the increased immune response against tumors [248]. T-bet is the main transcription factor involved in the differentiation of $\mathrm{CD}^{+}{ }^{+} \mathrm{T}$ cells in Th1 cells that are able to inhibit tumor growth and metastasis [248]. However, several studies have shown that tumor cells produce molecules that inhibit DC maturation such as IL-10, prostaglandin E2 (PGE2), and TGF- $\beta$ [249-251]. Nevertheless, it was shown that exercise training potentiates the synthesis of IFN- $y$, tumor necrosis factor (TNF)- $\alpha$ and IL-12, inducing an increase and maturation of DCs [248]. Additionally, recent evidence indicates that the practice of regular physical exercise also tends to increase the infiltration of CTLs in murine tumors [252]. Indeed, exercise training may represent an effective strategy to improve immune response. A study comparing healthy and tumorbearing animals concluded that physical exercise had a positive impact on macrophage function, which induced a reduction in metastasis [253]. On the contrary, sedentary tumor-bearing animals showed an increase in Th2 and Treg profile, resulting in a lower antitumor immune response and, consequently, facilitating the development of external tumor masses [254]. Furthermore, the typ- ically conversion of type 1 macrophages (M1) into type 2 (M2) seen in tumors produces higher levels of IL-10 and TGF- $\beta$, changing the differentiation of T cells away from a cytotoxic Th1 response $[255,256]$. IL-10 downregulates the adaptive immune response, inhibiting the activation of pro-inflammatory cytokines, further compromising the ability of effector T cells to maintain the inflammatory response [257]. Indeed, tumor-bearing animals exposed to long-term physical exercise developed less infiltrative and more benign histological lesions compared to sedentary tumor-bearing rats $[258,259]$. Exercise training may hinder the progression from non-invasive to invasive lesions by inhibiting uncontrolled cell proliferation and by increasing cell death, which partially explains the significant decrease in the total amount of malignant cells in exercised animals [259].

Similar to the remaining tissues, skeletal muscle contains resident immune cells to maintain homeostasis [260]. However, as pathological and physiological conditions like muscle contraction can induce chemical and mechanical stress threatening this condition, there is an additional infiltration of immune cells in skeletal muscles following physical exercise [261]. For immune cells to infiltrate skeletal muscle, the production of factors with attracting and activating properties is necessary [260]. Experimental evidence showed exercise-induced muscle production of several cytokines, including IL-6, IL-8, IL-10, IL-15, CC-chemokine ligand (CCL) 2, IL-1 receptor antagonist, and VEGF [262]. An important function of these cytokines in contracting muscles is to attract immune cells to control inflammatory processes and to support muscle regeneration following physical exercise [263]. Accordingly, Malm and colleagues observed that single bouts of eccentric exercise increased immune cell infiltration and inflammatory markers (CD11b, CD3 and HIF-1 $\beta$ ) in muscle epimysium [264]. Indeed, supporting the role of inflammatory response in muscles recovering from physical exercise, cDNA array analysis identified changes in gene products regulated by the NF-KB pathway such as CCL2, IL-18, C-X-C motif chemokine ligand 1 (CXCL1), leukemia inhibitory factor (LIF), and TGF- $\beta 1$ [265]. Of these, CCL2 regulates migration and infiltration of monocytes and macrophages in skeletal muscle, which are indispensible for tissue repair [260]. The macrophages that infiltrate the tissue earlier after injury are activated $\mathrm{M} 1$. They generate inflammatory cytokines and sustain the activation and the proliferation of muscle stem cells [266]. Alternatively, activated M2 predominates during the resolution phase, regulating the ending of the inflammatory response [267]. Monocyte-derived macrophages undergo dynamic transitions between $\mathrm{M} 1$ and $\mathrm{M} 2$ and this timely transition is increasingly felt to be the key to muscle homeostasis [268]. Indeed, although PMNs, including neutrophils and eosinophils, are the first leukocytes to be recruited into the tissue, macrophages accumulate shortly thereafter and subsequently become the dominant leukocyte population [269]. In contrast, the accumulation of $\mathrm{CD} 4^{+}$or $\mathrm{CD} 8^{+}$T lymphocytes reflects a persistent inflammatory or immune-mediated injury, such as that taking place as a consequence of muscular dystrophy or inflammatory myopathies [270]. The importance of these cellular adaptations in the health-promoting effects of physical exercise is further emphasized by the adverse effects of nonsteroidal anti-inflammatory drugs (NSAIDs) that inhibit the acute rise in skeletal muscle protein synthesis and the activation of satellite cells [271]. Therefore, these 
data support the role of physical exercise-induced immune response as a beneficial mechanism to a stress-inducing condition.

Taken together, these observations allow us to conclude that by contributing to the repair of tumor vasculature, physical exercise creates better conditions to improve antitumor immune response, systemically, by increasing Tbet gene and Th 1 cytokines expression and, locally, by providing superior access and function of immune cells ( $\triangleright$ Fig. 2).

\section{Conclusion}

The spatial and temporal heterogeneities in blood supply and vessel permeability associated with inefficient lymphatic drainage exacerbate the dysfunctional microenvironment that impairs a uniform distribution of $\mathrm{O}_{2}$ and therapeutic agents in tumors [50, 90, 272]. In addition, pharmacological approaches to restore tumor vasculature present transient effects and, in some cases, may increase tumor hypoxia, which is a strong stimulus for tumor cells to metastasize [273]. Since tumor vascular repair in response to physical exercise has been described, new hopes were raised to mitigate tumor aggressiveness that is intimately associated with hypoxic microenvironments. Taken together, these data suggest that exercise training has direct antioncogenic effects [252, 259, 274]. The mechanistic insight into the immunological role of physical exercise indicates that it may be able to mediate intratumoral adaptations, by triggering alterations in the TME that lead to vascular repair, enhancing tumor perfusion, oxygenation, and infiltration of immune cells [275]. Thus, the practice of regular physical exercise as a non-pharmacologic therapy for remodeling tumor vasculature may overcome the limitations associated with AIAs $[10,57]$. In addition to the associated adverse side effects, pharmacologic AIAs have a small therapeutic window with lower doses being ineffective and higher doses depleting too many vessels [45]. In contrast, it is unlikely that exercise training will over-prune tumor vasculature because capillaries adapt to chronic exercise by maturing and then becoming quiescent [276].

Globally, the available evidence suggests that exercise training may represent a valid therapeutic modality to the remodeling of tumor vasculature, improving TME and inhibiting tumor development. However, as the responses to physical exercise are complex and may be influenced by training parameters and by patients' socio-demographic variables, the results from pre-clinical investigations need to be replicated in the clinical setting, so additional studies are imperative.

\section{Conflict of Interest}

The authors declare, beyond the absence of any conflict of interest, that the manuscript complied with IJSM ethical standards [277].

\section{References}

[1] Fan F, Schimming A, Jaeger D et al. Targeting the tumor microenvironment: Focus on angiogenesis. J Oncol 2012; 2012: 281261. doi:10.1155/2012/281261
[2] Endrich B, Reinhold HS, Gross JF et al. Tissue perfusion inhomogeneity during early tumor growth in rats. J Natl Cancer Inst 1979; 62: 387-395

[3] Hendriksen EM, Span PN, Schuuring J et al. Angiogenesis, hypoxia and VEGF expression during tumour growth in a human xenograft tumour model. Microvasc Res 2009; 77: 96-103. doi:10.1016/j. mvr.2008.11.002

[4] Jain RK. Delivery of novel therapeutic agents in tumors: Physiological barriers and strategies. J Natl Cancer Inst 1989; 81: 570-576. doi:10.1093/jnci/81.8.570

[5] Schaaf MB, Garg AD, Agostinis P. Defining the role of the tumor vasculature in antitumor immunity and immunotherapy. Cell Death Dis 2018; 9: 115. doi:10.1038/s41419-017-0061-0

[6] Li X, Li Y, Lu W et al. The tumor vessel targeting strategy: A double-edged sword in tumor metastasis. Cells 2019; 8: 1602. doi: $10.3390 /$ cells 8121602

[7] Zhang X, Ashcraft KA, Betof Warner A et al. Can exercise-induced modulation of the tumor physiologic microenvironment improve antitumor immunity? Cancer Res 2019; 79: 2447-2456. doi:10.1158/0008-5472.CAN-18-2468

[8] Maj E, Papiernik D, Wietrzyk J. Antiangiogenic cancer treatment: The great discovery and greater complexity (Review). Int J Oncol 2016; 49: 1773-1784. doi:10.3892/ijo.2016.3709

[9] Horsman MR, Siemann DW. Pathophysiologic effects of vasculartargeting agents and the implications for combination with conventional therapies. Cancer Res 2006; 66: 11520-11539. doi:10.1158/0008-5472.CAN-06-2848

[10] Schadler KL, Thomas NJ, Galie PA et al. Tumor vessel normalization after aerobic exercise enhances chemotherapeutic efficacy. Oncotarget 2016; 7: 65429-65440. doi:10.18632/oncotarget.11748

[11] Ashcraft KA, Warner AB, Jones LW et al. Exercise as adjunct therapy in cancer. Semin Radiat Oncol 2019; 29: 16-24. doi:10.1016/j. semradonc.2018.10.001

[12] Gunnell AS, Joyce S, Tomlin S et al. Physical activity and survival among long-term cancer survivor and non-cancer cohorts. Front Public Health 2017; 5: 19. doi:10.3389/fpubh.2017.00019

[13] Siemann DW, Horsman MR. Modulation of the tumor vasculature and oxygenation to improve therapy. Pharmacol Ther 2015; 153 : 107-124. doi:10.1016/j.pharmthera.2015.06.006

[14] Saman H, Raza SS, Uddin S et al. Inducing angiogenesis, a key step in cancer vascularization, and treatment approaches. Cancers (Basel) 2020; 12: 1172. doi:10.3390/cancers12051172

[15] Lugano R, Ramachandran M, Dimberg A. Tumor angiogenesis: Causes, consequences, challenges and opportunities. Cell Mol Life Sci 2020; 77: 1745-1770. doi:10.1007/s00018-019-03351-7

[16] Dvorak HF. Angiogenesis: Update 2005. J Thromb Haemost 2005; 3: 1835-1842. doi:10.1111/j.1538-7836.2005.01361.x

[17] Nagy JA, Chang SH, Shih SC et al. Heterogeneity of the tumor vasculature. Semin Thromb Hemost 2010; 36: 321-331. doi:10.1055/s-0030-1253454

[18] Denekamp J. The tumour microcirculation as a target in cancer therapy: A clearer perspective. Eur J Clin Invest 1999; 29: 733-736. doi:10.1046/j.1365-2362.1999.00558.x

[19] Denekamp J, Hill S. Angiogenic attack as a therapeutic strategy for cancer. Radiother Oncol 1991; 20: 103-112. doi:10.1016/01678140(91)90196-n

[20] Hinnen P, Eskens FA. Vascular disrupting agents in clinical development. Br J Cancer 2007; 96: 1159-1165. doi:10.1038/sj.bjc.6603694

[21] Bridges E, Harris AL. Vascular-promoting therapy reduced tumor growth and progression by improving chemotherapy efficacy. Cancer Cell 2015; 27: 7-9. doi:10.1016/j.ccell.2014.12.009 
[22] Rajendran P, Rengarajan T, Thangavel J et al. The vascular endothelium and human diseases. Int J Biol Sci 2013; 9: 1057-1069. doi:10.7150/ijbs.7502

[23] Siemann DW. The unique characteristics of tumor vasculature and preclinical evidence for its selective disruption by tumor-vascular disrupting agents. Cancer Treat Rev 2011; 37: 63-74. doi:10.1016/j. ctrv.2010.05.001

[24] Horsman MR, Murata R. Combination of vascular targeting agents with thermal or radiation therapy. Int J Radiat Oncol Biol Phys 2002; 54: 1518-1523. doi:10.1016/s0360-3016(02)03926-3

[25] Seidi K, Jahanban-Esfahlan R, Zarghami N. Tumor rim cells: From resistance to vascular targeting agents to complete tumor ablation. Tumour Biol 2017; 39: 1010428317691001. doi:10.1177/101042 8317691001

[26] Rajabi M, Mousa SA. The role of angiogenesis in cancer treatment. Biomedicines 2017; 5: 34. doi:10.3390/biomedicines5020034

[27] Teleanu RI, Chircov C, Grumezescu AM et al. Tumor angiogenesis and anti-angiogenic strategies for cancer treatment. J Clin Med 2019; 9: 84. doi: $10.3390 / \mathrm{jcm} 9010084$

[28] Guyot M, Hilmi C, Ambrosetti D et al. Targeting the pro-angiogenic forms of VEGF or inhibiting their expression as anti-cancer strategies. Oncotarget 2017; 8: 9174-9188. doi:10.18632/oncotarget.13942

[29] Kunkel P, Ulbricht U, Bohlen P et al. Inhibition of glioma angiogenesis and growth in vivo by systemic treatment with a monoclonal antibody against vascular endothelial growth factor receptor- 2 . Cancer Res 2001; 61: 6624-6628

[30] Shaheen RM, Tseng WW, Vellagas R et al. Effects of an antibody to vascular endothelial growth factor receptor-2 on survival, tumor vascularity, and apoptosis in a murine model of colon carcinomatosis. Int J Oncol 2001; 18: 221-226

[31] Wedge SR, Ogilvie DJ, Dukes M et al. ZD6474 inhibits vascular endothelial growth factor signaling, angiogenesis, and tumor growth following oral administration. Cancer Res 2002; 62: 4645-4655

[32] Beecken WD, Fernandez A, Joussen AM et al. Effect of antiangiogenic therapy on slowly growing, poorly vascularized tumors in mice. J Natl Cancer Inst 2001; 93: 382-387. doi:10.1093/jnci/93.5.382

[33] Batchelor TT, Gerstner ER, Emblem KE et al. Improved tumor oxygenation and survival in glioblastoma patients who show increased blood perfusion after cediranib and chemoradiation. Proc Natl Acad Sci USA 2013; 110: 19059-19064. doi:10.1073/ pnas. 1318022110

[34] Tong RT, Boucher Y, Kozin SV et al. Vascular normalization by vascular endothelial growth factor receptor 2 blockade induces a pressure gradient across the vasculature and improves drug penetration in tumors. Cancer Res 2004; 64: 3731-3736. doi:10.1158/0008-5472. CAN-04-0074

[35] Dvorak HF. Vascular permeability factor/vascular endothelial growth factor: A critical cytokine in tumor angiogenesis and a potential target for diagnosis and therapy. J Clin Oncol 2002; 20: 4368-4380. doi:10.1200/JCO.2002.10.088

[36] Siemann DW, Chaplin DJ, Horsman MR. Vascular-targeting therapies for treatment of malignant disease. Cancer 2004; 100: 2491-2499. doi:10.1002/cncr.20299

[37] Ribatti D, Annese T, Ruggieri S et al. Limitations of anti-angiogenic treatment of tumors. Transl Oncol 2019; 12: 981-986. doi:10.1016/j. tranon.2019.04.022

[38] Stebbing J, Waters L, Davies L et al. Incidence of cancer in individuals receiving chronic zopiclone or eszopiclone requires prospective study. J Clin Oncol 2005; 23: 8134-8136. doi:10.1200/ JCO.2005.03.5881

[39] Nakahara T, Norberg SM, Shalinsky DR et al. Effect of inhibition of vascular endothelial growth factor signaling on distribution of extravasated antibodies in tumors. Cancer Res 2006; 66: 1434-1445. doi:10.1158/0008-5472.CAN-05-0923
[40] Morgan B, Thomas AL, Drevs J et al. Dynamic contrast-enhanced magnetic resonance imaging as a biomarker for the pharmacological response of PTK787/ZK 222584, an inhibitor of the vascular endothelial growth factor receptor tyrosine kinases, in patients with advanced colorectal cancer and liver metastases: Results from two phase I studies. J Clin Oncol 2003; 21: 3955-3964. doi:10.1200/ JCO.2003.08.092

[41] Ebos JM, Lee CR, Cruz-Munoz W et al. Accelerated metastasis after short-term treatment with a potent inhibitor of tumor angiogenesis. Cancer Cell 2009; 15: 232-239. doi:10.1016/j.ccr.2009.01.021

[42] Paez-Ribes M, Allen E, Hudock J et al. Antiangiogenic therapy elicits malignant progression of tumors to increased local invasion and distant metastasis. Cancer Cell 2009; 15: 220-231. doi:10.1016/j. ccr.2009.01.027

[43] Siemann DW, Shi W. Efficacy of combined antiangiogenic and vascular disrupting agents in treatment of solid tumors. Int J Radiat Oncol Biol Phys 2004; 60: 1233-1240. doi:10.1016/j. ijrobp.2004.08.002

[44] Jahanban-Esfahlan R, Seidi K, Manjili MH et al. Tumor cell dormancy: Threat or opportunity in the fight against cancer. Cancers (Basel) 2019; 11: 1207. doi:10.3390/cancers11081207

[45] Martin JD, Seano G, Jain RK. Normalizing function of tumor vessels: Progress, opportunities, and challenges. Annu Rev Physiol 2019; 81: 505-534. doi:10.1146/annurev-physiol-020518-114700

[46] Roskoski R Jr.. Vascular endothelial growth factor (VEGF) signaling in tumor progression. Crit Rev Oncol Hematol 2007; 62: 179-213. doi:10.1016/j.critrevonc.2007.01.006

[47] Fukumura D, Duda DG, Munn LL et al. Tumor microvasculature and microenvironment: Novel insights through intravital imaging in pre-clinical models. Microcirculation 2010; 17: 206-225. doi:10.1111/j.1549-8719.2010.00029.x

[48] Ehling M, Mazzone M. Vessel normalization in the spot-LIGHT of cancer treatment. Trends Mol Med 2016; 22: 85-87. doi:10.1016/j. molmed.2015.12.009

[49] Jain RK. Antiangiogenesis strategies revisited: From starving tumors to alleviating hypoxia. Cancer Cell 2014; 26: 605-622. doi:10.1016/j. ccell.2014.10.006

[50] Jain RK, Martin JD, Stylianopoulos T. The role of mechanical forces in tumor growth and therapy. Annu Rev Biomed Eng 2014; 16 : 321-346. doi:10.1146/annurev-bioeng-071813-105259

[51] Goel S, Wong AH, Jain RK. Vascular normalization as a therapeutic strategy for malignant and nonmalignant disease. Cold Spring Harb Perspect Med 2012; 2: a006486. doi:10.1101/cshperspect.a006486

[52] Leite de Oliveira R, Deschoemaeker S, Henze AT et al. Gene-targeting of Phd2 improves tumor response to chemotherapy and prevents side-toxicity. Cancer Cell 2012; 22: 263-277. doi:10.1016/j. ccr.2012.06.028

[53] Li W, Quan YY, Li Y et al. Monitoring of tumor vascular normalization: The key points from basic research to clinical application. Cancer Manag Res 2018; 10: 4163-4172. doi:10.2147/CMAR.S174712

[54] Goel S, Duda DG, Xu L et al. Normalization of the vasculature for treatment of cancer and other diseases. Physiol Rev 2011; 91 : 1071-1121. doi:10.1152/physrev.00038.2010

[55] Jain RK. Normalization of tumor vasculature: An emerging concept in antiangiogenic therapy. Science 2005; 307: 58-62. doi:10.1126/ science. 1104819

[56] Cantelmo AR, Pircher A, Kalucka J et al. Vessel pruning or healing: Endothelial metabolism as a novel target? Expert Opin Ther Targets 2017; 21: 239-247. doi:10.1080/14728222.2017.1282465

[57] Morrell MBG, Alvarez-Florez C, Zhang A et al. Vascular modulation through exercise improves chemotherapy efficacy in Ewing sarcoma. Pediatr Blood Cancer 2019; 66: e27835. doi:10.1002/pbc.27835 
[58] Betof AS, Lascola CD, Weitzel D et al. Modulation of murine breast tumor vascularity, hypoxia and chemotherapeutic response by exercise. J Natl Cancer Inst 2015; 107. doi:10.1093/jnci/djv040

[59] McCullough DJ, Nguyen LM, Siemann DW et al. Effects of exercise training on tumor hypoxia and vascular function in the rodent preclinical orthotopic prostate cancer model. J Appl Physiol (1985) 2013; 115: 1846-1854. doi:10.1152/japplphysiol.00949.2013

[60] McCullough D], Stabley JN, Siemann DW et al. Modulation of blood flow, hypoxia, and vascular function in orthotopic prostate tumors during exercise. J Natl Cancer Inst 2014; 106: dju036. doi:10.1093/ jnci/dju036

[61] Brown MD. Exercise and coronary vascular remodeling in the healthy heart. Exp Physiol 2003; 88: 645-658. doi:10.1113/eph8802618

[62] Yang HT, Ren J, Laughlin MH et al. Prior exercise training produces NO-dependent increases in collateral blood flow after acute arterial occlusion. Am J Physiol Heart Circ Physiol 2002; 282: H301-H310. doi:10.1152/ajpheart.00160.2001

[63] Schirmer SH, Millenaar DN, Werner C et al. Exercise promotes collateral artery growth mediated by monocytic nitric oxide. Arterioscler Thromb Vasc Biol 2015; 35: 1862-1871. doi:10.1161/ ATVBAHA.115.305806

[64] Hellsten Y, Nyberg M, Jensen LG et al. Vasodilator interactions in skeletal muscle blood flow regulation. J Physiol 2012; 590: 62976305. doi:10.1113/jphysiol.2012.240762

[65] Jones LW, Viglianti BL, Tashjian JA et al. Effect of aerobic exercise on tumor physiology in an animal model of human breast cancer. J Appl Physiol (1985) 2010; 108: 343-348. doi:10.1152/japplphysiol.00424.2009

[66] Qiu Y, Myers DR, Lam WA. The biophysics and mechanics of blood from a materials perspective. Nat Rev Mater 2019; 4: 294-311. doi:10.1038/s41578-019-0099-y

[67] Atkinson CL, Carter HH, Naylor LH et al. Opposing effects of shear-mediated dilation and myogenic constriction on artery diameter in response to handgrip exercise in humans. J Appl Physiol (1985) 2015; 119: 858-864. doi:10.1152/japplphysiol.01086.2014

[68] Kojda G, Hambrecht R. Molecular mechanisms of vascular adaptations to exercise. Physical activity as an effective antioxidant therapy? Cardiovasc Res 2005; 67: 187-197. doi:10.1016/j.cardiores.2005.04.032

[69] Tzima E, Irani-Tehrani M, Kiosses WB et al. A mechanosensory complex that mediates the endothelial cell response to fluid shear stress. Nature 2005; 437: 426-431. doi:10.1038/nature03952

[70] Ballermann B], Ott M]. Adhesion and differentiation of endothelial cells by exposure to chronic shear stress: a vascular graft model. Blood Purif 1995; 13: 125-134. doi:10.1159/000170195

[71] Green DJ, Hopman MT, Padilla J et al. Vascular adaptation to exercise in humans: Role of hemodynamic stimuli. Physiol Rev 2017; 97 : 495-528. doi:10.1152/physrev.00014.2016

[72] Chang YS, di Tomaso E, McDonald DM et al. Mosaic blood vessels in tumors: frequency of cancer cells in contact with flowing blood. Proc Natl Acad Sci USA 2000; 97: 14608-14613. doi:10.1073/ pnas.97.26.14608

[73] Goetz JG. Metastases go with the flow. Science 2018; 362: 9991000. doi: $10.1126 /$ science.aat 9100

[74] Jain RK. Determinants of tumor blood flow: A review. Cancer Res 1988; 48: 2641-2658

[75] Hashizume H, Baluk P, Morikawa S et al. Openings between defective endothelial cells explain tumor vessel leakiness. Am J Pathol 2000; 156: 1363-1380. doi:10.1016/S0002-9440(10)65006-7

[76] Hobbs SK, Monsky WL, Yuan F et al. Regulation of transport pathways in tumor vessels: Role of tumor type and microenvironment. Proc Natl Acad Sci USA 1998; 95: 4607-4612. doi:10.1073/ pnas.95.8.4607
[77] Yuan F, Salehi HA, Boucher $Y$ et al. Vascular permeability and microcirculation of gliomas and mammary carcinomas transplanted in rat and mouse cranial windows. Cancer Res 1994; 54: 4564-4568

[78] Potenta S, Zeisberg E, Kalluri R. The role of endothelial-to-mesenchymal transition in cancer progression. Br J Cancer 2008; 99: 13751379. doi:10.1038/sj.bjc.6604662

[79] Baluk P, Hashizume H, McDonald DM. Cellular abnormalities of blood vessels as targets in cancer. Curr Opin Genet Dev 2005; 15: 102-111. doi:10.1016/j.gde.2004.12.005

[80] Ozawa MG, Yao V], Chanthery YH et al. Angiogenesis with pericyte abnormalities in a transgenic model of prostate carcinoma. Cancer 2005; 104: 2104-2115. doi:10.1002/cncr.21436

[81] Baluk P, Morikawa S, Haskell A et al. Abnormalities of basement membrane on blood vessels and endothelial sprouts in tumors. Am J Pathol 2003; 163: 1801-1815. doi:10.1016/S0002-9440(10)63540-7

[82] Jung B, Obinata H, Galvani S et al. Flow-regulated endothelial S1P receptor-1 signaling sustains vascular development. Dev Cell 2012; 23: 600-610. doi:10.1016/j.devcel.2012.07.015

[83] Hughes SK, Wacker BK, Kaneda MM et al. Fluid shear stress modulates cell migration induced by sphingosine 1-phosphate and vascular endothelial growth factor. Ann Biomed Eng 2005; 33: 1003-1014. doi:10.1007/s10439-005-5756-1

[84] Zhao J, Garcia D, Gartung A et al. Sphingosine-1-phosphate receptor subtype 2 signaling in endothelial senescence-associated functional impairments and inflammation. Curr Atheroscler Rep 2015; 17: 504. doi:10.1007/s11883-015-0504-y

[85] Cattoretti G, Mandelbaum J, Lee $\mathrm{N}$ et al. Targeted disruption of the S1P2 sphingosine 1-phosphate receptor gene leads to diffuse large B-cell lymphoma formation. Cancer Res 2009; 69: 8686-8692. doi:10.1158/0008-5472.CAN-09-1110

[86] Carmeliet P, Jain RK. Principles and mechanisms of vessel normalization for cancer and other angiogenic diseases. Nat Rev Drug Discov 2011; 10: 417-427. doi:10.1038/nrd3455

[87] Jaszai J, Schmidt MHH. Trends and challenges in tumor anti-angiogenic therapies. Cells 2019; 8: 1102. doi:10.3390/cells8091102

[88] Dellian M, Witwer BP, Salehi HA et al. Quantitation and physiological characterization of angiogenic vessels in mice: Effect of basic fibroblast growth factor, vascular endothelial growth factor/vascular permeability factor, and host microenvironment. Am J Pathol 1996; 149: 59-71

[89] Zhou Y, Wang W, Wei R et al. Serum bradykinin levels as a diagnostic marker in cervical cancer with a potential mechanism to promote VEGF expression via BDKRB2. Int J Oncol 2019; 55: 131-141. doi:10.3892/ijo.2019.4792

[90] Stylianopoulos T, Munn LL, Jain RK. Reengineering the physical microenvironment of tumors to improve drug delivery and efficacy: From mathematical modeling to bench to bedside. Trends Cancer 2018; 4: 292-319. doi:10.1016/j.trecan.2018.02.005

[91] Tredan O, Galmarini CM, Patel K et al. Drug resistance and the solid tumor microenvironment. J Natl Cancer Inst 2007; 99: 1441-1454. doi:10.1093/jnci/djm135

[92] Boucher Y, Jain RK. Microvascular pressure is the principal driving force for interstitial hypertension in solid tumors: Implications for vascular collapse. Cancer Res 1992; 52: 5110-5114

[93] Gao Y, Shi Y, Fu M et al. Simulation study of the effects of interstitial fluid pressure and blood flow velocity on transvascular transport of nanoparticles in tumor microenvironment. Comput Methods Programs Biomed 2020; 193: 105493. doi:10.1016/j. cmpb.2020.105493

[94] Jang SH, Wientjes MG, Lu D et al. Drug delivery and transport to solid tumors. Pharm Res 2003; 20: 1337-1350. doi:10.1023/a:1025785505977 
[95] Graham K, Unger E. Overcoming tumor hypoxia as a barrier to radiotherapy, chemotherapy and immunotherapy in cancer treatment. Int J Nanomedicine 2018; 13: 6049-6058. doi:10.2147/IJN.S140462

[96] Jain RK, Stylianopoulos T. Delivering nanomedicine to solid tumors. Nat Rev Clin Oncol 2010; 7: 653-664. doi:10.1038/nrclinonc.2010.139

[97] Vaupel P, Kallinowski F, Okunieff P. Blood flow, oxygen and nutrient supply, and metabolic microenvironment of human tumors: A review. Cancer Res 1989; 49: 6449-6465

[98] Hori K, Suzuki M, Tanda S et al. In vivo analysis of tumor vascularization in the rat. Jpn J Cancer Res 1990; 81: 279-288. doi:10.1111/j.1349-7006.1990.tb02562.x

[99] Hori K, Suzuki M, Tanda $S$ et al. Characterization of heterogeneous distribution of tumor blood flow in the rat. Jpn J Cancer Res 1991; 82: 109-117. doi:10.1111/j.1349-7006.1991.tb01753.x

[100] Forster JC, Harriss-Phillips WM, Douglass MJ et al. A review of the development of tumor vasculature and its effects on the tumor microenvironment. Hypoxia (Auckl) 2017; 5: 21-32. doi:10.2147/ HP.S133231

[101] Petrova V, Annicchiarico-Petruzzelli M, Melino G et al. The hypoxic tumour microenvironment. Oncogenesis 2018; 7: 10. doi:10.1038/ s41389-017-0011-9

[102] Jing $X$, Yang $F$, Shao $C$ et al. Role of hypoxia in cancer therapy by regulating the tumor microenvironment. Mol Cancer 2019; 18: 157. doi:10.1186/s12943-019-1089-9

[103] Hellsten Y, Nyberg M. Cardiovascular adaptations to exercise training. Compr Physiol 2015; 6: 1-32. doi:10.1002/cphy.c140080

[104] Sarelius I, Pohl U. Control of muscle blood flow during exercise: local factors and integrative mechanisms. Acta Physiol (Oxf) 2010; 199: 349-365. doi:10.1111/j.1748-1716.2010.02129.x

[105] Bagher P, Segal SS. Regulation of blood flow in the microcirculation: role of conducted vasodilation. Acta Physiol (Oxf) 2011; 202: 271-284. doi:10.1111/j.1748-1716.2010.02244.x

[106] Cohen KD, Berg BR, Sarelius IH. Remote arteriolar dilations in response to muscle contraction under capillaries. Am J Physiol Heart Circ Physiol 2000; 278: H1916-H1923. doi:10.1152/ ajpheart.2000.278.6.H1916

[107] Garcia E, Becker VG, McCullough D] et al. Blood flow responses to mild-intensity exercise in ectopic vs. orthotopic prostate tumors; Dependence upon host tissue hemodynamics and vascular reactivity. J Appl Physiol (1985) 2016; 121: 15-24. doi:10.1152/japplphysiol.00266.2016

[108] Rowell LB. Human cardiovascular adjustments to exercise and thermal stress. Physiol Rev 1974; 54: 75-159. doi:10.1152/ physrev.1974.54.1.75

[109] Mishra RC, Rahman MM, Davis MJ et al. Alpha1 -adrenergic stimulation selectively enhances endothelium-mediated vasodilation in rat cremaster arteries. Physiol Rep 2018; 6: e13703. doi:10.14814/ phy2.13703

[110] Matsukawa K. Central command: control of cardiac sympathetic and vagal efferent nerve activity and the arterial baroreflex during spontaneous motor behaviour in animals. Exp Physiol 2012; 97 : 20-28. doi:10.1113/expphysiol.2011.057661

[111] White DW, Raven PB. Autonomic neural control of heart rate during dynamic exercise: Revisited. J Physiol 2014; 592: 2491-2500. doi:10.1113/jphysiol.2014.271858

[112] Tschakovsky ME, Sujirattanawimol K, Ruble SB et al. Is sympathetic neural vasoconstriction blunted in the vascular bed of exercising human muscle? J Physiol 2002; 541: 623-635. doi:10.1113/ jphysiol.2001.014431
[113] Mortensen SP, Nyberg M, Gliemann L et al. Exercise training modulates functional sympatholysis and alpha-adrenergic vasoconstrictor responsiveness in hypertensive and normotensive individuals. J Physiol 2014; 592: 3063-3073. doi:10.1113/jphysiol.2014.273722

[114] Heinonen I, Wendelin-Saarenhovi M, Kaskinoro K et al. Inhibition of alpha-adrenergic tone disturbs the distribution of blood flow in the exercising human limb. Am J Physiol Heart Circ Physiol 2013; 305: H163-H172. doi:10.1152/ajpheart.00925.2012

[115] McGee MC, Hamner JB, Williams RF et al. Improved intratumoral oxygenation through vascular normalization increases glioma sensitivity to ionizing radiation. Int J Radiat Oncol Biol Phys 2010; 76: 1537-1545. doi:10.1016/j.jijrobp.2009.12.010

[116] Missiaen R, Mazzone M, Bergers G. The reciprocal function and regulation of tumor vessels and immune cells offers new therapeutic opportunities in cancer. Semin Cancer Biol 2018; 52: 107-116. doi:10.1016/j.semcancer.2018.06.002

[117] Martin JD, Fukumura D, Duda DG et al. Reengineering the tumor microenvironment to alleviate hypoxia and overcome cancer heterogeneity. Cold Spring Harb Perspect Med 2016; 6: a027094. doi:10.1101/cshperspect.a027094

[118] Seynhaeve ALB, Amin M, Haemmerich D et al. Hyperthermia and smart drug delivery systems for solid tumor therapy. Adv Drug Deliv Rev 2020. Online ahead of print. doi:10.1016/j.addr.2020.02.004

[119] Nacev A, Kim SH, Rodriguez-Canales J et al. A dynamic magnetic shift method to increase nanoparticle concentration in cancer metastases: A feasibility study using simulations on autopsy specimens. Int ] Nanomedicine 2011; 6: 2907-2923. doi:10.2147/JJN.S23724

[120] Dewhirst MW, Secomb TW. Transport of drugs from blood vessels to tumour tissue. Nat Rev Cancer 2017; 17: 738-750. doi:10.1038/ nrc.2017.93

[121] Aukland K, Reed RK. Interstitial-lymphatic mechanisms in the control of extracellular fluid volume. Physiol Rev 1993; 73: 1-78. doi:10.1152/physrev.1993.73.1.1

[122] Jacob M, Chappell D, Becker BF. Regulation of blood flow and volume exchange across the microcirculation. Crit Care 2016; 20: 319. doi:10.1186/s13054-016-1485-0

[123] Heldin CH, Rubin K, Pietras K et al. High interstitial fluid pressure - an obstacle in cancer therapy. Nat Rev Cancer 2004; 4: 806-813. doi:10.1038/nrc1456

[124] Carraway RE, Cochrane DE. Enhanced vascular permeability is hypothesized to promote inflammation-induced carcinogenesis and tumor development via extravasation of large molecular proteins into the tissue. Med Hypotheses 2012; 78: 738-743. doi:10.1016/j. mehy.2012.02.021

[125] Horsman MR, Vaupel P. Pathophysiological basis for the formation of the tumor microenvironment. Front Oncol 2016; 6: 66. doi:10.3389/ fonc.2016.00066

[126] Garnier L, Gkountidi AO, Hugues S. Tumor-associated lymphatic vessel features and immunomodulatory functions. Front Immunol 2019; 10: 720. doi:10.3389/fimmu.2019.00720

[127] Simonsen TG, Gaustad JV, Leinaas MN et al. High interstitial fluid pressure is associated with tumor-line specific vascular abnormalities in human melanoma xenografts. PLoS One 2012; 7: e40006. doi:10.1371/journal.pone.0040006

[128] Munson JM, Shieh AC. Interstitial fluid flow in cancer: Implications for disease progression and treatment. Cancer Manag Res 2014; 6: 317-328. doi:10.2147/CMAR.S65444

[129] Wagner M, Wiig H. Tumor interstitial fluid formation, characterization, and clinical implications. Front Oncol 2015; 5: 115. doi:10.3389/fonc.2015.00115

[130] Boucher Y, Baxter LT, Jain RK. Interstitial pressure gradients in tissue-isolated and subcutaneous tumors: Implications for therapy. Cancer Res 1990; 50: 4478-4484 
[131] Padera TP, Stoll BR, Tooredman JB et al. Pathology: cancer cells compress intratumour vessels. Nature 2004; 427: 695. doi:10.1038/427695a

[132] Prabhakar U, Maeda H, Jain RK et al. Challenges and key considerations of the enhanced permeability and retention effect for nanomedicine drug delivery in oncology. Cancer Res 2013; 73 : 2412-2417. doi:10.1158/0008-5472.CAN-12-4561

[133] Padera TP, Kadambi A, di Tomaso E et al. Lymphatic metastasis in the absence of functional intratumor lymphatics. Science 2002; 296: 1883-1886. doi:10.1126/science. 1071420

[134] Wei R, Liu S, Zhang S et al. Cellular and extracellular components in tumor microenvironment and their application in early diagnosis of cancers. Anal Cell Pathol (Amst) 2020; 2020: 6283796. doi:10.1155/2020/6283796

[135] Shang M, Soon RH, Lim CT et al. Microfluidic modelling of the tumor microenvironment for anti-cancer drug development. Lab Chip 2019; 19: 369-386. doi:10.1039/c8lc00970h

[136] Mori T, Koga T, Shibata H et al. Interstitial fluid pressure correlates clinicopathological factors of lung cancer. Ann Thorac Cardiovasc Surg 2015; 21: 201-208. doi:10.5761/atcs.oa.14-00208

[137] Milosevic M, Fyles A, Hedley D et al. Interstitial fluid pressure predicts survival in patients with cervix cancer independent of clinical prognostic factors and tumor oxygen measurements. Cancer Res 2001; 61: 6400-6405

[138] van der Voort van Zyp J, Thamilselvan V, Walsh M et al. Extracellular pressure stimulates colon cancer cell adhesion in vitro and to surgical wounds by Src (sarcoma protein) activation. Am J Surg 2004; 188: 467-473. doi:10.1016/j.amjsurg.2004.07.005

[139] Rofstad EK, Galappathi K, Mathiesen BS. Tumor interstitial fluid pressure-a link between tumor hypoxia, microvascular density, and lymph node metastasis. Neoplasia 2014; 16: 586-594. doi:10.1016/j. neo.2014.07.003

[140] Jain RK, Tong RT, Munn LL. Effect of vascular normalization by antiangiogenic therapy on interstitial hypertension, peritumor edema, and lymphatic metastasis: Insights from a mathematical model. Cancer Res 2007; 67: 2729-2735. doi:10.1158/0008-5472. CAN-06-4102

[141] Gillen CM, Lee R, Mack GW et al. Plasma volume expansion in humans after a single intense exercise protocol. J Appl Physiol (1985) 1991; 71: 1914-1920. doi:10.1152/jappl.1991.71.5.1914

[142] Gillen CM, Nishiyasu T, Langhans G et al. Cardiovascular and renal function during exercise-induced blood volume expansion in men. J Appl Physiol (1985) 1994; 76: 2602-2610. doi:10.1152/jappl.1994.76.6.2602

[143] Nagashima K, Cline GW, Mack GW et al. Intense exercise stimulates albumin synthesis in the upright posture. J Appl Physiol (1985) 2000; 88: 41-46. doi:10.1152/jappl.2000.88.1.41

[144] Mack GW, Yang R, Hargens AR et al. Influence of hydrostatic pressure gradients on regulation of plasma volume after exercise. J Appl Physiol (1985) 1998; 85: 667-675. doi:10.1152/jappl.1998.85.2.667

[145] Haskell A, Nadel ER, Stachenfeld NS et al. Transcapillary escape rate of albumin in humans during exercise-induced hypervolemia. J Appl Physiol (1985) 1997; 83: 407-413. doi:10.1152/jappl.1997.83.2.407

[146] Zawieja DC. Contractile physiology of lymphatics. Lymphat Res Biol 2009; 7: 87-96. doi:10.1089//rb.2009.0007

[147] Reed RK, Rubin K. Transcapillary exchange: role and importance of the interstitial fluid pressure and the extracellular matrix. Cardiovasc Res 2010; 87: 211-217. doi:10.1093/cvr/cvq143

[148] Denekamp J, Hobson B. Endothelial-cell proliferation in experimental tumors. Br J Cancer 1982; 46: 711-720. doi:10.1038/bjc.1982.263

[149] Vaupel P, Hockel M. Blood supply, oxygenation status and metabolic micromilieu of breast cancers: characterization and therapeutic relevance. Int J Oncol 2000; 17: 869-879. doi:10.3892/ijo.17.5.869
[150] Helmlinger G, Yuan F, Dellian M et al. Interstitial pH and pO2 gradients in solid tumors in vivo: High-resolution measurements reveal a lack of correlation. Nat Med 1997; 3: 177-182. doi:10.1038/ nm0297-177

[151] Bertout JA, Patel SA, Simon MC. The impact of $O 2$ availability on human cancer. Nat Rev Cancer 2008; 8: 967-975. doi:10.1038/ $\operatorname{nrc} 2540$

[152] Bayer C, Shi K, Astner ST et al. Acute versus chronic hypoxia: why a simplified classification is simply not enough. Int J Radiat Oncol Biol Phys 2011; 80: 965-968. doi:10.1016/j.jrobp.2011.02.049

[153] Hockel M, Vaupel P. Tumor hypoxia: definitions and current clinical, biologic, and molecular aspects. J Natl Cancer Inst 2001; 93: 266-276. doi:10.1093/jnci/93.4.266

[154] Kolstad P. Intercapillary distance, oxygen tension and local recurrence in cervix cancer. Scand J Clin Lab Invest Suppl 1968; 106 : 145-157

[155] Vaupel P, Mayer A, Hockel M. Tumor hypoxia and malignant progression. Methods Enzymol 2004; 381: 335-354. doi:10.1016/ S0076-6879(04)81023-1

[156] Kaelin WG Jr.. The VHL tumor suppressor gene: Insights into oxygen sensing and cancer. Trans Am Clin Climatol Assoc 2017; 128: 298-307

[157] Nakayama K, Kataoka N. Regulation of gene expression under hypoxic conditions. Int J Mol Sci 2019; 20: 3278. doi:10.3390/ ijms20133278

[158] Semenza GL. Targeting HIF-1 for cancer therapy. Nat Rev Cancer 2003; 3: 721-732. doi:10.1038/nrc1187

[159] Wang Y, Wang H, Li J et al. Direct visualization of the phenotype of hypoxic tumor cells at single cell resolution in vivo using a new hypoxia probe. Intravital. 2016; 5: e1187803. doi:10.1080/21659087 .2016 .1187803

[160] Muz B, de la Puente P, Azab F et al. The role of hypoxia in cancer progression, angiogenesis, metastasis, and resistance to therapy. Hypoxia (Auckl) 2015; 3: 83-92. doi:10.2147/HP.S93413

[161] Semenza GL. Oxygen sensing, hypoxia-inducible factors, and disease pathophysiology. Annu Rev Pathol 2014; 9: 47-71. doi:10.1146/ annurev-pathol-012513-104720

[162] Brizel DM, Scully SP, Harrelson JM et al. Tumor oxygenation predicts for the likelihood of distant metastases in human soft tissue sarcoma. Cancer Res 1996; 56: 941-943

[163] Hasan NM, Adams GE, Joiner MC et al. Hypoxia facilitates tumour cell detachment by reducing expression of surface adhesion molecules and adhesion to extracellular matrices without loss of cell viability. $\mathrm{Br}$ J Cancer 1998; 77: 1799-1805. doi:10.1038/bjc.1998.299

[164] Young SD, Marshall RS, Hill RP. Hypoxia induces DNA overreplication and enhances metastatic potential of murine tumor cells. Proc Natl Acad Sci USA 1988; 85: 9533-9537. doi:10.1073/pnas.85.24.9533

[165] Dewhirst MW. A potential solution for eliminating hypoxia as a cause for radioresistance. Proc Natl Acad Sci USA 2018; 115: 10548-10550. doi:10.1073/pnas.1814212115

[166] Sharma A, Arambula JF, Koo $S$ et al. Hypoxia-targeted drug delivery. Chem Soc Rev 2019; 48: 771-813. doi:10.1039/c8cs00304a

[167] Yokoyama C, Sueyoshi Y, Ema M et al. Induction of oxidative stress by anticancer drugs in the presence and absence of cells. Oncol Lett 2017; 14: 6066-6070. doi:10.3892/ol.2017.6931

[168] Kim SJ, Kim HS, Seo YR. Understanding of ROS-inducing strategy in anticancer therapy. Oxid Med Cell Longev 2019; 2019: 5381692. doi:10.1155/2019/5381692

[169] Wang H, Jiang $\mathrm{H}$, Van De Gucht $M$ et al. Hypoxic Radioresistance: Can ROS be the key to overcome it? Cancers (Basel) 2019; 11: 112 . doi:10.3390/cancers 11010112 
[170] Wilson WR, Hay MP. Targeting hypoxia in cancer therapy. Nat Rev Cancer 2011; 11: 393-410. doi:10.1038/nrc3064

[171] Ferreira LF, Poole DC, Barstow TJ. Muscle blood flow-O2 uptake interaction and their relation to on-exercise dynamics of $\mathrm{O} 2$ exchange. Respir Physiol Neurobiol 2005; 147: 91-103. doi:10.1016/j.resp.2005.02.002

[172] Perko MJ, Nielsen HB, Skak C et al. Mesenteric, coeliac and splanchnic blood flow in humans during exercise. J Physiol 1998; 513: 907-913. doi:10.1111/j.1469-7793.1998.907ba.x

[173] Endo MY, Suzuki R, Nagahata $N$ et al. Differential arterial blood flow response of splanchnic and renal organs during low-intensity cycling exercise in women. Am J Physiol Heart Circ Physiol 2008; 294: H2322-H2326. doi:10.1152/ajpheart.91491.2007

[174] Fry BC, Roy TK, Secomb TW. Capillary recruitment in a theoretical model for blood flow regulation in heterogeneous microvessel networks. Physiol Rep 2013; 1: e00050. doi:10.1002/phy2.50

[175] Radak Z, Zhao Z, Koltai E et al. Oxygen consumption and usage during physical exercise: the balance between oxidative stress and ROS-dependent adaptive signaling. Antioxid Redox Signal 2013; 18 : 1208-1246. doi:10.1089/ars.2011.4498

[176] Ortiz-Prado E, Dunn JF, Vasconez ] et al. Partial pressure of oxygen in the human body: a general review. Am J Blood Res 2019; 9: 1-14

[177] Pittman RN. Oxygen transport in the microcirculation and its regulation. Microcirculation 2013; 20: 117-137. doi:10.1111/ micc. 12017

[178] Pittman RN. Oxygen supply to contracting skeletal muscle at the microcirculatory level: diffusion vs. convection. Acta Physiol Scand 2000; 168: 593-602. doi:10.1046/j.1365-201x.2000.00710.x

[179] Cardinale DA, Larsen F], Jensen-Urstad $M$ et al. Muscle mass and inspired oxygen influence oxygen extraction at maximal exercise: role of mitochondrial oxygen affinity. Acta Physiol (Oxf) 2019; 225: e13110. doi:10.1111/apha.13110

[180] Joyner MJ, Casey DP. Regulation of increased blood flow (hyperemia) to muscles during exercise: a hierarchy of competing physiological needs. Physiol Rev 2015; 95: 549-601. doi:10.1152/physrev.00035.2013

[181] Lindholm ME, Rundqvist $\mathrm{H}$. Skeletal muscle hypoxia-inducible factor-1 and exercise. Exp Physiol 2016; 101: 28-32. doi:10.1113/ EP085318

[182] Skattebo O, Capelli C, Rud B et al. Increased oxygen extraction and mitochondrial protein expression after small muscle mass endurance training. Scand J Med Sci Sports 2020; 30: 1615-1631. doi:10.1111/ sms. 13707

[183] Rud B, Foss O, Krustrup P et al. One-legged endurance training: leg blood flow and oxygen extraction during cycling exercise. Acta Physiol (Oxf) 2012; 205: 177-185. doi:10.1111/j.1748-1716.2011.02383.x

[184] Lundby C, Gassmann M, Pilegaard H. Regular endurance training reduces the exercise induced HIF-1alpha and HIF-2alpha mRNA expression in human skeletal muscle in normoxic conditions. Eur J Appl Physiol 2006; 96: 363-369. doi:10.1007/s00421-005-0085-5

[185] Lindholm ME, Fischer $\mathrm{H}$, Poellinger $\mathrm{L}$ et al. Negative regulation of HIF in skeletal muscle of elite endurance athletes: a tentative mechanism promoting oxidative metabolism. Am J Physiol Regul Integr Comp Physiol 2014; 307: R248-R255. doi:10.1152/ajpregu.00036.2013

[186] Gatenby RA, Gawlinski ET, Gmitro AF et al. Acid-mediated tumor invasion: a multidisciplinary study. Cancer Res 2006; 66: 5216-5223. doi:10.1158/0008-5472.CAN-05-4193

[187] Gatenby RA, Gillies RJ. Why do cancers have high aerobic glycolysis? Nat Rev Cancer 2004; 4: 891-899. doi:10.1038/nrc1478
[188] Kallinowski F, Vaupel P, Runkel S et al. Glucose uptake, lactate release, ketone body turnover, metabolic micromilieu, and $\mathrm{pH}$ distributions in human breast cancer xenografts in nude rats. Cancer Res 1988; 48 : 7264-7272

[189] Luo Z, Loja MN, Farwell DG et al. Widefield optical imaging of changes in uptake of glucose and tissue extracellular $\mathrm{pH}$ in head and neck cancer. Cancer Prev Res (Phila) 2014; 7: 1035-1044. doi:10.1158/1940-6207.CAPR-14-0097

[190] Loja MN, Luo Z, Greg Farwell D et al. Optical molecular imaging detects changes in extracellular $\mathrm{pH}$ with the development of head and neck cancer. Int J Cancer 2013; 132: 1613-1623. doi:10.1002/ ijc. 27837

[191] Griffiths JR. Are cancer cells acidic? Br J Cancer 1991; 64: 425-427. doi:10.1038/bjc.1991.326

[192] Avnet S, Chano T, Massa A et al. Acid microenvironment promotes cell survival of human bone sarcoma through the activation of CIAP proteins and NF-kappaB pathway. Am J Cancer Res 2019; 9: 1127-1144

[193] de la Cruz-Lopez KG, Castro-Munoz LJ, Reyes-Hernandez DO et al. Lactate in the regulation of tumor microenvironment and therapeutic approaches. Front Oncol 2019; 9: 1143. doi:10.3389/ fonc. 2019.01143

[194] Gerweck LE. Tumor pH: implications for treatment and novel drug design. Semin Radiat Oncol 1998; 8: 176-182. doi:10.1016/ s1053-4296(98)80043-x

[195] Kallinowski F, Runkel S, Fortmeyer HP et al. L-glutamine: A major substrate for tumor cells in vivo? J Cancer Res Clin Oncol 1987; 113: 209-215. doi:10.1007/BF00396375

[196] Longo DL, Bartoli A, Consolino L et al. In vivo imaging of tumor metabolism and acidosis by combining PET and MRI-CEST pH imaging. Cancer Res 2016; 76: 6463-6470. doi:10.1158/0008-5472. CAN-16-0825

[197] Jiang B. Aerobic glycolysis and high level of lactate in cancer metabolism and microenvironment. Genes Dis 2017; 4: 25-27. doi:10.1016/j.gendis.2017.02.003

[198] Al Tameemi W, Dale TP, Al-Jumaily RMK et al. Hypoxia-modified cancer cell metabolism. Front Cell Dev Biol 2019; 7: 4. doi:10.3389/ fcell.2019.00004

[199] Gillies RJ, Gatenby RA. Metabolism and its sequelae in cancer evolution and therapy. Cancer J 2015; 21: 88-96. doi:10.1097/ PPO.0000000000000102

[200] Fais S, Venturi G, Gatenby B. Microenvironmental acidosis in carcinogenesis and metastases: new strategies in prevention and therapy. Cancer Metastasis Rev 2014; 33: 1095-1108. doi:10.1007| s10555-014-9531-3

[201] Kato Y, Ozawa S, Miyamoto C et al. Acidic extracellular microenvironment and cancer. Cancer Cell Int 2013; 13: 89. doi:10.1186/14752867-13-89

[202] Gerweck LE, Vijayappa S, Kozin S. Tumor pH controls the in vivo efficacy of weak acid and base chemotherapeutics. Mol Cancer Ther 2006; 5: 1275-1279. doi:10.1158/1535-7163.MCT-06-0024

[203] Faes S, Uldry E, Planche A et al. Acidic $\mathrm{PH}$ reduces VEGF-mediated endothelial cell responses by downregulation of VEGFR-2; relevance for anti-angiogenic therapies. Oncotarget 2016; 7: 86026-86038. doi:10.18632/oncotarget.13323

[204] Kolosenko I, Avnet S, Baldini N et al. Therapeutic implications of tumor interstitial acidification. Semin Cancer Biol 2017; 43: 119-133. doi:10.1016/j.semcancer.2017.01.008

[205] Aveseh M, Nikooie R, Aminaie M. Exercise-induced changes in tumour LDH-B and MCT1 expression are modulated by oestrogen-related receptor alpha in breast cancer-bearing BALB/c mice. J Physiol 2015; 593: 2635-2648. doi:10.1113/JP270463 
[206] Bacurau RF, Belmonte MA, Seelaender MC et al. Effect of a moderate intensity exercise training protocol on the metabolism of macrophages and lymphocytes of tumour-bearing rats. Cell Biochem Funct 2000; 18: 249-258. doi:10.1002/10990844(200012)18:4<249::AID-CBF879>3.0.CO;2-2

[207] Juel C. Regulation of pH in human skeletal muscle: adaptations to physical activity. Acta Physiol (Oxf) 2008; 193: 17-24. doi:10.1111/ j.1748-1716.2008.01840.x

[208] Stickland MK, Lindinger MI, Olfert IM et al. Pulmonary gas exchange and acid-base balance during exercise. Compr Physiol 2013; 3: 693-739. doi:10.1002/cphy.c110048

[209] Wasserman K, Cox TA, Sietsema KE. Ventilatory regulation of arterial $\mathrm{H}(+)(\mathrm{pH})$ during exercise. Respir Physiol Neurobiol 2014; 190 : 142-148. doi:10.1016/j.resp.2013.10.009

[210] Pilegaard H, Domino K, Noland T et al. Effect of high-intensity exercise training on lactate/ $\mathrm{H}+$ transport capacity in human skeletal muscle. Am J Physiol 1999; 276: E255-E261. doi:10.1152/ ajpendo.1999.276.2.E255

[211] Juel C. Regulation of cellular pH in skeletal muscle fiber types, studied with sarcolemmal giant vesicles obtained from rat muscles. Biochim Biophys Acta 1995; 1265: 127-132. doi:10.1016/01674889(94)00209-w

[212] Juel C, Holten MK, Dela F. Effects of strength training on muscle lactate release and MCT1 and MCT4 content in healthy and type 2 diabetic humans. J Physiol 2004; 556: 297-304. doi:10.1113/ jphysiol.2003.058222

[213] Pilegaard H, Bangsbo J, Richter EA et al. Lactate transport studied in sarcolemmal giant vesicles from human muscle biopsies: relation to training status. J Appl Physiol (1985) 1994; 77: 1858-1862. doi:10.1152/jappl.1994.77.4.1858

[214] Thomas C, Bishop D, Moore-Morris T et al. Effects of high-intensity training on MCT1, MCT4, and NBC expressions in rat skeletal muscles: influence of chronic metabolic alkalosis. Am J Physiol Endocrinol Metab 2007; 293: E916-E922. doi:10.1152/ajpendo.00164.2007

[215] Nielsen JJ, Mohr M, Klarskov C et al. Effects of high-intensity intermittent training on potassium kinetics and performance in human skeletal muscle. J Physiol 2004; 554: 857-870. doi:10.1113/ jphysiol.2003.050658

[216] Anderson KG, Stromnes IM, Greenberg PD. Obstacles posed by the tumor microenvironment to $T$ cell activity: a case for synergistic therapies. Cancer Cell 2017; 31: 311-325. doi:10.1016/j. ccell.2017.02.008

[217] Park SL, Gebhardt T, Mackay LK. Tissue-resident memory T cells in cancer immunosurveillance. Trends Immunol 2019; 40: 735-747. doi:10.1016/j.it.2019.06.002

[218] Paardekooper LM, Vos W, van den Bogaart G. Oxygen in the tumor microenvironment: effects on dendritic cell function. Oncotarget 2019; 10: 883-896. doi:10.18632/oncotarget.26608

[219] Vito A, El-Sayes N, Mossman K. Hypoxia-driven immune escape in the tumor microenvironment. Cells 2020; 9: 992. doi:10.3390/ cells9040992

[220] Huber V, Camisaschi C, Berzi A et al. Cancer acidity: an ultimate frontier of tumor immune escape and a novel target of immunomodulation. Semin Cancer Biol 2017; 43: 74-89. doi:10.1016/j. semcancer.2017.03.001

[221] Gajewski TF, Fuertes M, Spaapen R et al. Molecular profiling to identify relevant immune resistance mechanisms in the tumor microenvironment. Curr Opin Immunol 2011; 23: 286-292. doi:10.1016/j.coi.2010.11.013

[222] Davoodzadeh Gholami M, Kardar GA, Saeedi Y et al. Exhaustion of T lymphocytes in the tumor microenvironment: significance and effective mechanisms. Cell Immunol 2017; 322: 1-14. doi:10.1016/j. cellimm.2017.10.002
[223] Krzywinska E, Stockmann C. Hypoxia, metabolism and immune cell function. Biomedicines 2018; 6: 56. doi:10.3390/biomedicines 6020056

[224] Lin Y, Xu J, Lan H. Tumor-associated macrophages in tumor metastasis: biological roles and clinical therapeutic applications. J Hematol Oncol 2019; 12: 76. doi:10.1186/s13045-019-0760-3

[225] Labiano S, Palazon A, Melero I. Immune response regulation in the tumor microenvironment by hypoxia. Semin Oncol 2015; 42: 378-386. doi:10.1053/j.seminoncol.2015.02.009

[226] Kondoh M, Ohga N, Akiyama K et al. Hypoxia-induced reactive oxygen species cause chromosomal abnormalities in endothelial cells in the tumor microenvironment. PLoS One 2013; 8: e80349. doi:10.1371/journal.pone.0080349

[227] Xu-Monette ZY, Zhang M, Li J et al. PD-1/PD-L1 Blockade: Have we found the key to unleash the antitumor immune response? Front Immunol 2017; 8: 1597. doi:10.3389/fimmu.2017.01597

[228] Song X, Zhang Y, Zhang $L$ et al. Hypoxia enhances indoleamine 2,3-dioxygenase production in dendritic cells. Oncotarget 2018; 9: 11572-11580. doi:10.18632/oncotarget.24098

[229] Prendergast GC, Smith C, Thomas S et al. Indoleamine 2,3-dioxygenase pathways of pathogenic inflammation and immune escape in cancer. Cancer Immunol Immunother 2014; 63: 721-735. doi:10.1007/s00262-014-1549-4

[230] Kiraga L, Cheda L, Taciak B et al. Changes in hypoxia level of CT26 tumors during various stages of development and comparing different methods of hypoxia determination. PLoS One 2018; 13 : e0206706. doi:10.1371/journal.pone.0206706

[231] Conforti L. Potassium channels of T lymphocytes take center stage in the fight against cancer. J Immunother Cancer. 2017; 5: 2. doi:10.1186/s40425-016-0202-5

[232] Eil R, Vodnala SK, Clever D et al. lonic immune suppression within the tumour microenvironment limits T cell effector function. Nature 2016; 537: 539-543. doi:10.1038/nature19364

[233] Renner K, Singer K, Koehl GE et al. Metabolic hallmarks of tumor and immune cells in the tumor microenvironment. Front Immunol 2017; 8: 248. doi:10.3389/fimmu.2017.00248

[234] Brand A, Singer K, Koehl GE et al. LDHA-associated lactic acid production blunts tumor immunosurveillance by T and NK cells. Cell Metab 2016; 24: 657-671. doi:10.1016/j.cmet.2016.08.011

[235] Lardner A. The effects of extracellular $\mathrm{pH}$ on immune function. J Leukoc Biol 2001; 69: 522-530

[236] Gkretsi V, Stylianou A, Papageorgis P et al. Remodeling components of the tumor microenvironment to enhance cancer therapy. Front Oncol 2015; 5: 214. doi:10.3389/fonc.2015.00214

[237] Calcinotto A, Filipazzi P, Grioni M et al. Modulation of microenvironment acidity reverses anergy in human and murine tumor-infiltrating T lymphocytes. Cancer Res 2012; 72: 2746-2756. doi:10.1158/00085472.CAN-11-1272

[238] Soriano C, Mukaro V, Hodge G et al. Increased proteinase inhibitor-9 (PI-9) and reduced granzyme $B$ in lung cancer: mechanism for immune evasion? Lung Cancer 2012; 77: 38-45. doi:10.1016/j. lungcan.2012.01.017

[239] Gottfried E, Kunz-Schughart LA, Ebner S et al. Tumor-derived lactic acid modulates dendritic cell activation and antigen expression. Blood 2006; 107: 2013-2021. doi:10.1182/blood-2005-05-1795

[240] Bellone M, Calcinotto A, Filipazzi P et al. The acidity of the tumor microenvironment is a mechanism of immune escape that can be overcome by proton pump inhibitors. Oncoimmunology 2013; 2: e22058. doi:10.4161/onci.22058

[241] Caruana I, Simula L, Locatelli F et al. T lymphocytes against solid malignancies: winning ways to defeat tumors. Cell Stress 2018; 2: 200-212. doi:10.15698/cst2018.07.148 
[242] Hojman P, Gehl J, Christensen JF et al. Molecular mechanisms linking exercise to cancer prevention and treatment. Cell Metab 2018; 27: 10-21. doi:10.1016/j.cmet.2017.09.015

[243] Nielsen HB, Secher NH, Kappel M et al. Lymphocyte, NK and LAK cell responses to maximal exercise. Int J Sports Med 1996; 17: 60-65. doi:10.1055/s-2007-972809

[244] Walsh NP, Gleeson M, Pyne DB et al. Position statement. Part two: Maintaining immune health. Exerc Immunol Rev 2011; 17: 64-103

[245] Koelwyn G], Wennerberg E, Demaria $S$ et al. Exercise in regulation of inflammation-immune axis function in cancer initiation and progression. Oncology (Williston Park) 2015; 29: 908-920

[246] Stromberg A, Rullman E, Jansson E et al. Exercise-induced upregulation of endothelial adhesion molecules in human skeletal muscle and number of circulating cells with remodeling properties. J Appl Physiol (1985) 2017; 122: 1145-1154. doi:10.1152/japplphysiol.00956.2016

[247] Campbell JP, Riddell NE, Burns VE et al. Acute exercise mobilises CD8 + T lymphocytes exhibiting an effector-memory phenotype. Brain Behav Immun 2009; 23: 767-775. doi:10.1016/j. bbi.2009.02.011

[248] Bianco TM, Abdalla DR, Desiderio CS et al. The influence of physical activity in the anti-tumor immune response in experimental breast tumor. Immunol Lett 2017; 190: 148-158. doi:10.1016/j.imlet. 2017.08.007

[249] DeVito NC, Plebanek MP, Theivanthiran B et al. Role of tumor-mediated dendritic cell tolerization in immune evasion. Front Immunol 2019; 10: 2876. doi:10.3389/fimmu.2019.02876

[250] Kim R, Emi M, Tanabe K. Cancer cell immune escape and tumor progression by exploitation of anti-inflammatory and pro-inflammatory responses. Cancer Biol Ther 2005; 4: 924-933. doi:10.4161/ cbt.4.9.2101

[251] Kusmartsev S, Gabrilovich DI. Effect of tumor-derived cytokines and growth factors on differentiation and immune suppressive features of myeloid cells in cancer. Cancer Metastasis Rev 2006; 25: 323-331. doi:10.1007/s10555-006-9002-6

[252] Pedersen L, Idorn M, Olofsson GH et al. Voluntary running suppresses tumor growth through epinephrine- and IL-6-dependent NK cell mobilization and redistribution. Cell Metab 2016; 23: 554-562. doi:10.1016/j.cmet.2016.01.011

[253] Ashcraft KA, Peace RM, Betof AS et al. Efficacy and mechanisms of aerobic exercise on cancer initiation, progression, and metastasis: a critical systematic review of in vivo preclinical data. Cancer Res 2016; 76: 4032-4050. doi:10.1158/0008-5472.CAN-16-0887

[254] Abdalla DR, Murta EF, Michelin MA. The influence of physical activity on the profile of immune response cells and cytokine synthesis in mice with experimental breast tumors induced by 7,12-dimethylbenzanthracene. Eur J Cancer Prev 2013; 22: 251-258. doi:10.1097| CEJ.0b013e3283592cbb

[255] Qi L, Yu H, Zhang Y et al. IL-10 secreted by M2 macrophage promoted tumorigenesis through interaction with JAK2 in glioma. Oncotarget 2016; 7: 71673-71685. doi:10.18632/oncotarget.12317

[256] Kwasniak K, Czarnik-Kwasniak ], Maziarz A et al. Scientific reports concerning the impact of interleukin 4, interleukin 10 and transforming growth factor beta on cancer cells. Cent Eur I Immunol 2019; 44: 190-200. doi:10.5114/ceji.2018.76273

[257] Maynard CL, Weaver CT. Diversity in the contribution of interleukin-10 to T-cell-mediated immune regulation. Immunol Rev 2008; 226: 219-233. doi:10.1111/j.1600-065X.2008.00711.x

[258] Faustino-Rocha Al, Silva A, Gabriel ] et al. Long-term exercise training as a modulator of mammary cancer vascularization. Biomed Pharmacother 2016; 81: 273-280. doi:10.1016/j.biopha. 2016.04.030

[259] Figueira ACC, Figueira MC, Silva C et al. Exercise training-induced modulation in microenvironment of rat mammary neoplasms. Int J Sports Med 2018; 39: 885-892. doi:10.1055/a-0660-0198
[260] Pillon N], Bilan P], Fink LN et al. Cross-talk between skeletal muscle and immune cells: muscle-derived mediators and metabolic implications. Am J Physiol Endocrinol Metab 2013; 304: E453-E465. doi:10.1152/ajpendo.00553.2012

[261] Yang W, Hu P. Skeletal muscle regeneration is modulated by inflammation. J Orthop Translat 2018; 13: 25-32. doi:10.1016/j. jot.2018.01.002

[262] Peake JM, Della Gatta P, Suzuki K et al. Cytokine expression and secretion by skeletal muscle cells: regulatory mechanisms and exercise effects. Exerc Immunol Rev 2015; 21: 8-25

[263] Hoffmann C, Weigert C. Skeletal muscle as an endocrine organ: the role of myokines in exercise adaptations. Cold Spring Harb Perspect Med 2017; 7: a029793. doi:10.1101/cshperspect.a029793

[264] Malm C, Sjodin TL, Sjoberg B et al. Leukocytes, cytokines, growth factors and hormones in human skeletal muscle and blood after uphill or downhill running. J Physiol 2004; 556: 983-1000. doi:10.1113/jphysiol.2003.056598

[265] Hyldahl RD, Xin L, Hubal M] et al. Activation of nuclear factor-kappaB following muscle eccentric contractions in humans is localized primarily to skeletal muscle-residing pericytes. FASEB | 2011; 25: 2956-2966. doi:10.1096/fj.10-177105

[266] Arnold L, Henry A, Poron F et al. Inflammatory monocytes recruited after skeletal muscle injury switch into anti-inflammatory macrophages to support myogenesis. J Exp Med 2007; 204: 1057-1069. doi:10.1084/jem.20070075

[267] Ruffell D, Mourkioti F, Gambardella A et al. A CREB-C/EBPbeta cascade induces $\mathrm{M} 2$ macrophage-specific gene expression and promotes muscle injury repair. Proc Natl Acad Sci USA 2009; 106: 17475-17480. doi:10.1073/pnas.0908641106

[268] Mosser DM, Edwards JP. Exploring the full spectrum of macrophage activation. Nat Rev Immunol 2008; 8: 958-969. doi:10.1038/nri2448

[269] Chazaud B. Macrophages: supportive cells for tissue repair and regeneration. Immunobiology 2014; 219: 172-178. doi:10.1016/j. imbio.2013.09.001

[270] Villalta SA, Rosenthal W, Martinez L et al. Regulatory T cells suppress muscle inflammation and injury in muscular dystrophy. Sci Transl Med 2014; 6: 258ra142. doi:10.1126/scitranslmed.3009925

[271] Trappe TA, Carroll CC, Dickinson JM et al. Influence of acetaminophen and ibuprofen on skeletal muscle adaptations to resistance exercise in older adults. Am J Physiol Regul Integr Comp Physiol 2011; 300: R655-R662. doi:10.1152/ajpregu.00611.2010

[272] Zhang B, Hu Y, Pang Z. Modulating the tumor microenvironment to enhance tumor nanomedicine delivery. Front Pharmacol 2017; 8: 952. doi:10.3389/fphar.2017.00952

[273] De Bock K, Mazzone M, Carmeliet P. Antiangiogenic therapy, hypoxia, and metastasis: risky liaisons, or not? Nat Rev Clin Oncol 2011; 8: 393-404. doi:10.1038/nrclinonc.2011.83

[274] Hvid T, Lindegaard B, Winding K et al. Effect of a 2-year home-based endurance training intervention on physiological function and PSA doubling time in prostate cancer patients. Cancer Causes Control 2016; 27: 165-174. doi:10.1007/s10552-015-0694-1

[275] Idorn M, Hojman P. Exercise-dependent regulation of NK cells in cancer protection. Trends Mol Med 2016; 22: 565-577. doi:10.1016/j.molmed.2016.05.007

[276] Di Francescomarino S, Sciartilli A, Di Valerio $V$ et al. The effect of physical exercise on endothelial function. Sports Med 2009; 39: 797-812. doi:10.2165/11317750-000000000-00000

[277] Harriss D], MacSween A, Atkinson G. Ethical standards in sport and exercise science research: 2020 update. Int J Sports Med 2019; 40 813-817. doi:10.1055/a-1015-3123 